\title{
UNA INTERPRETACIÓN DEL IMPACTO DE LAS MAQUILADORAS EN EL BIENESTAR FAMILIAR Y EN EL DESARROLLO REGIONAL
}

\author{
Por \\ Mario M. Carrillo Huerta*
}

\begin{abstract}
RESUMEN
En este trabajo se presenta una evaluación de los impactos de las maquiladoras en las condiciones de vida de la comunidad. Las apreciaciones referentes al impacto de la maquila en el bienestar familiar se basan en una muestra aplicada a 1,200 trabajadores en 4 ciudades. Los resultados obtenidos parecen indicar que, en términos generales y en relación con algunas variables de bienestar, la situación de los trabajadores ha mejorado como consecuencia de su empleo en la maquiladora. Noobstante, existen diferencias entre las variables consideradas, pues mientras los puntajes más altos corresponden a alimentación y vestido, los más bajos se encontraron en vivienda, transporte y servicios de salud.
\end{abstract}

\begin{abstract}
In this work, an evaluation of the maquiladora impact on community life conditions is presented. Apreciations referring maquila impact on family wellbeing are based on a survey made with 1,200 workers in 4 cities. The results seem to indicate that in general terms and in relation to some well-being variables, the workers situation has improved as a consequence of their employment in maquiladora industry. Nevertheless, there are differences among the variables considered, since while the highest ecores are those of food and clothing, the lowest ones are found in housing, transportion and health services.
\end{abstract}

\section{INTRODUCCIÓN}

Por lo menos durante los últimos 20 años, las maquiladoras en México han aumentado en número y actividad casi ininterrumpidamente. Sin embargo, han sido objeto de permanente polémica, tanto en el ámbito académico como en el de la política económica.

Por ejemplo, se ha argumentado que no obstante sus efectos positivos aparentes en variables macroeconómicas como el empleo, los ingresos y

- Doctor en economía. Actualmente profesor de Desarrollo regional y urbano en la Universidad de las Américas en Puebla. 
las divisas, las maquiladoras han afectado negativamente el bienestar familiar al través de sus impactos en la organización familiar, vía su selectividad en términos de estructura laboral, y en el desarrollo regional, vía sus crecientes demandas de servicios y de trato preferencial.

En este trabajo se presenta una evaluación de los impactos de las maquiladoras en las condiciones de vida de la comunidad. Las apreciaciones referentes al impacto de la maquila en el bienestar familiar se basan en una muestra de 1,200 trabajadores, y aquéllas relacionadas con los aspectos más generales e importantes de la maquila en la vida de las localidades donde operan, se derivan de una muestra de 40 líderes de opinión. Tales apreciaciones fueron captadas al través del trabajo de campo realizado por el autor entre diciembre de 1988 y enero de 1989, entre 300 trabajadores maquiladores y 10 líderes de opinión de cada una de las ciudades fronterizas de Tijuana, Ciudad Juárez y Nuevo Laredo y de la no fronteriza de Guadalajara, todo como parte de un estudio más amplio patrocinado por la Comission for the Study of International Migration and Cooperative Economic Development (COSIMCED) del Congreso de los Estados Unidos de Norteamérica.

El trabajo consta de tres secciones. En la primera sección se describe el programa mexicano de maquiladoras y su evolución en los últimos 20 años. Ahí se presentan las características del programa en términos de la localización de las plantas, su grado de integración a la economía nacional y su transferencia tecnológica, así como de su estructura laboral.

En la segunda sección se describen las características de la encuesta y se presentan los resultados generales en relación a la estructura laboral de la industria.

En la última sección, se incluye la evaluación de los impactos de las maquiladoras en el bienestar de las familias de los trabajadores, visto por ellos mismos, y del impacto de esa industria en la vida de la comunidad, visto por los líderes de opinión locales.

En términos generales, en el trabajo se muestra que los trabajadores maquiladores piensan que su empleo en la industria ha tenido efectos positivos en el bienestar de sus familias, mientras que los líderes de opinión encuentran efectos muy positivos en el desarrollo regional, en los ingresos y en las condiciones de vida de la comunidad.

\section{LA INDUSTRIA MAQUILADORA EN MÉXICO}

La participación de varios países en la producción de un bien determinado, o maquila, surgió como respuesta de algunas empresas de países industrializados a la creciente competencia internacional que, combinada con el cambio 
técnico, las había hecho poco competitivas en el mercado. ${ }^{1}$ Dichas empresas abatían costos y mantenían competitividad trasladando parte de sus procesos de producción a otros países donde la mano de obra era significativamente más barata, dichas empresas abatían costos y mantenían competitividad.

En el caso de México, los factores que más han influido en el establecimiento de plantas maquiladoras, en su mayoría filiales de empresas estadounidenses, han sido las ventajas económicas de mercado (salarios y de tipo de cambio), las ventajas de política económica en Estados Unidos y en México, y la ventaja obvia de la cercanía entre ambos países.

\section{Los impactos macroeconómicos de las maquiladoras}

Todas esas ventajas son las principales responsables del crecimiento inusitado de esta actividad en el país durante los últimos años. El número de maquiladoras en México ha aumentado casi ininterrumpidamente desde 1970 hasta 1988 , de 120 pasó a 1,396 plantas. Hubo en consecuencia aumentos considerables casi ininterrumpidamente en el número total de empleos y divisas generados y en la derrama de salarios. Mientras que entre 1970 y 1988 el número de plantas aumentó 11.6 veces, el del total de empleados aumentó 18.2 veces; las divisas totales generadas se incrementaron cerca de 20.8 veces, y los salarios totales derramados por las maquiladoras y calculados en dólares aumentaron 9.6 veces (véase cuadro 1 ).

1 Tal vez una de las fuentes más recientes y más completas que analizan este fenómeno es: Joseph Grunwald y Kenneth Flamm, The Global Factory. Foreign Assembly in International Trade. Washington, D. C.: The Brookings Institution, 1985. Aunque no se conoce con precisión la fecha en que se inició este fenómeno, esos autores mencionan que, por lo menos en la industria de los semiconductores, el inicio puede haber sido 1961, cuando el productor Fairchild estableció una filial en Hong Kong para exportar al mercado norteamericano (p. 69).

2 En efecto, el programa mexicano de maquiladoras formó parte integral del Programa de industrialización de la frontera norte de 1965 , que tenía como objetivopromoverla industrialización en la zona y dar empleo a un alto número de mexicanos desocupados por la terminación del Programa Bracero, quienes ofrecían su trabajo por salarios bastante menores que los que se pagaban en Estados Unidos. Por otro lado, y por lo menos a partir de 1982, las devaluaciones consecutivas del peso mexicano llevaron de una sobrevaluación promedio del $21.6 \%$ en 1981 , a una subvaluación del $20.3 \%$ en 1982 ; del $37.9 \%$ en 1983 ; del $16.2 \%$ en 1984 ; del $22.7 \%$ en 1985 y de $37.5 \%$ en 1987, a partir de cuando empezó a tender progresivamente a su valor de equilibrio. En cuanto a la tarifa aduanera norteamericana, las fracciones 9802.00 .60 (antes 806.30) y 9802.00 .80 (antes 807.0) del Sistema Armonizado de Tarifas establecen gravamen sólo a la importación del valor del procesamiento en el exterior de componentes norteamericanos. En cuanto a la posición original mexicana, el artículo 321 del Código Aduanero permitió la importación libre de materiales y equipo para la producción, siempre que se localizara a no más de 90 kilómetros de distancia de la línea fronteriza y reexportara el $100 \%$ de la producción. Recientemente, se introdujo en la legislación mexicana cierta flexibilidad en la localización y en el destino de las ventas (véase Mario M. Carrillo Huerta y Víctor Urquidi, 1989). 
CUADRO 1. México: Plantas maquiladoras, 1970-1988.

\begin{tabular}{|c|c|c|c|c|}
\hline Año & $\begin{array}{l}\text { Núm. de } \\
\text { plantas } \\
\text { (a) }\end{array}$ & $\begin{array}{l}\text { Empleos } \\
\text { generados } \\
\text { (b) }\end{array}$ & $\begin{array}{l}\text { Divisas generadas } \\
\text { (mill. de dólares) } \\
\text { (c) }\end{array}$ & $\begin{array}{l}\text { Salar. y prest. } \\
\text { Totales } \\
\text { (mill. de dólares) } \\
\text { (d) }\end{array}$ \\
\hline 1970 & 120 & 20327 & 82.9 & n.d. \\
\hline 1971 & 251 & 29214 & 101.9 & n.d. \\
\hline 1972 & 339 & 40060 & 155.5 & n.d. \\
\hline 1973 & 357 & 64330 & 238.6 & 115.5 \\
\hline 1974 & 455 & 75977 & 375.1 & 194.7 \\
\hline 1975 & 454 & 67213 & 332.4 & 194.4 \\
\hline 1976 & 443 & 74496 & 365.6 & 215.6 \\
\hline 1977 & 448 & 78433 & 344.6 & 200.3 \\
\hline 1978 & 457 & 90704 & 452.3 & 262.5 \\
\hline 1979 & 540 & 111365 & 638.0 & 371.4 \\
\hline 1980 & 620 & 119546 & 771.0 & 456.4 \\
\hline 1981 & 605 & 130973 & 976.0 & 597.7 \\
\hline 1982 & 585 & 127048 & 851.3 & 445.8 \\
\hline 1983 & 600 & 150867 & 829.5 & 390.7 \\
\hline 1984 & 672 & 199684 & 1155.0 & 543.8 \\
\hline 1985 & 760 & 211968 & 1267.0 & 540.4 \\
\hline 1986 & 891 & 249833 & 1285.0 & 564.3 \\
\hline 1987 & 1125 & 305253 & 1572.5 & 676.8 \\
\hline 1988 & 1396 & 369489 & 1726.4 & 728.7 \\
\hline
\end{tabular}

FUENTE: Número de plantas y de empleos (columnas a y b): 1970-1983, Joseph Grunwald y Kenneth Flamm, The Global Factory Foreingn Assembly in International Trade. Cuadro 4-1, p.140; 1984-1986, Instituto Nacional de Estadística, Geografía e Informática, Avance de información económica. Industria maquiladora de exportación, Mayo, 1987. Cuadro 1, p. 5, y marzo, 1989, cuadro 2, p.6, para 1987-1988.

Divisas generadas (columna c): 1970-1983, Sergio Rivas F., "La industria maquiladora en México", Comercio Exterior, vol. 35, no. 11 (noviembre de 1985), cuadro 13, p. 1081; 1984-1988, Wharton Econometric Forecasting Associates, Perspectivas económicas de México,Vol. XIX, no. 3. Cuadro 10, p. 194; y vol. XX, no. 4, Cuadro 17, p. 240.

Salarios y prestaciones (columna d): 1973-1983, Grunwald y Flamm, op cit., cuadro 4-2, p. 143. 1984-1988, calculado a partir de datos en pesos mexicanos de INEGI, op. cit., y de tipo de cambio de Banco de México, Informe Anual, varios volúmenes, y Wharton Econometric Forecasting Associates, op. cit., Cuadro 15, p. 238. 
Igualmente creciente ha sido la participación de las maquiladoras en los valores de las principales variables nacionales. Las divisas generadas por las maquiladoras pasaron del $12.7 \%$ del total de las exportaciones de mercancías no petroleras en 1975 , al $13.2 \%$ en 1988 , habiendo llegado al 20.1 en 1981. (véase cuadro 2). ${ }^{3}$

CUADRO 2. México: Participación relativa de las plantas maquiladoras en agregados nacionales seleccionados, 19701988, (porcentajes).

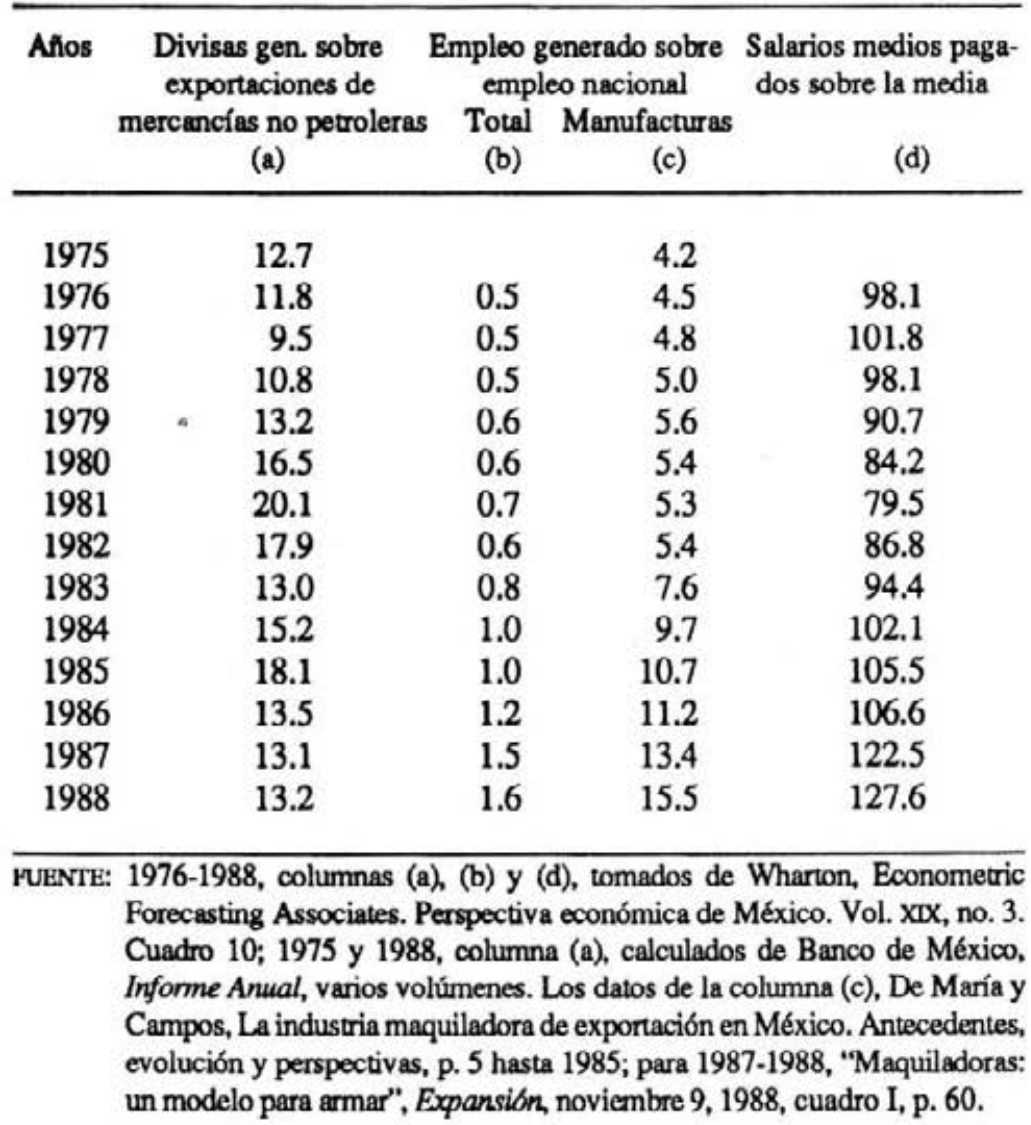

3 De hecho, considerada individualmente, la cuenta de servicios de transformación (léase maquiladoras) de la balanza de pagos de México en 1985 y 1986, fue la segunda cuenta más importante en la generación de divisas, superada solamente por las exportaciones de petróleo crudo. Véase Banco de México, Indicadores económicos, diciembre de 1986, cuadro Iv-5, p. Iv-8. 
El empleo generado por las plantas maquiladoras en 1976 equivalió a $0.5 \%$ del empleo nacional, y se elevó al $1.0 \%$ en 1984-1986, llegando hasta el $1.6 \%$ en 1988 . Sin embargo, considerando sólo el empleo nacional en la industria manufacturera, la participación de las maquiladoras casi se cuadruplico entre 1975 y 1988 , de $4.2 \%$ a $15.5 \%$. En cuanto a los salarios medios pagados en la industria maquiladora, comparados con los salarios medios nacionales durante 1976-1986, declinaron a un nivel de $79.5 \%$ en 1981, y acusaron tendencia al alza a partir de entonces (véase cuadro 2).

No obstante la significancia de la participación global de la actividad de las maquiladoras, un análisis a nivel menos agregado indica efectos diferentes que dependen de la localización geográfica de las plantas y del tipo de producto que elaboran.

\section{Localización geográfica de las plantas}

Desde el punto de vista de la localización geográfica, las maquiladoras se han concentrado históricamente en la región fronteriza del norte de México, debido en parte a la legislación mexicana que, hasta 1983 , obligaba a las empresas a localizarse en una franja de 20 kilometros a partir de la línea divisoria México-Estados Unidos y a exportar el $100 \%$ de su producción, y también en buena medida a que la región fronteriza es el punto geográfico más cercano al mercado estadounidense donde se pueden aprovechar las ventajas salariales y de tipo de cambio que ofrece México. Alrededor del $90 \%$ del número de plantas, del empleo generado y del valor agregado producido correspondi 6 , hasta 1988, a dicha zona fronteriza, por lo que la maquiladora se entiende en México como un fenómeno todavía eminentemente fronterizo (véase cuadro 3$)^{4}$

\section{Tipo de productos maquilados}

La fuerte concentración de las maquiladoras en la frontera norte es evidencia de su orientación hacia el mercado estadounidense y de que el

4 De los datos incluidos en el cuadro se desprende que, a nivel agregado, la frontera no solamente tiene el mayor número de maquiladoras, sino que, además, sus empleados se llevan una proporción relativamente mayor de los salarios y prestaciones pagadas, al mismo tiempo que producen un por ciento menor (tambien relativamente) del valor agregado que los de las plantas del resto del país. En 1980 las ciudades que más maquiladoras tenían (de un total de 620), fueron Tijuana (123), Ciudad Juárez (121), Mexicali (79), Nogales (59) Matamoros (50), y Agua Prieta (22). (Véase Grunwald y Flamm, 1985, p. 148). En enero de 1989 de un total de 1,518 empresas, Tijuana tuvo 400; Ciudad Juárez, 253; Mexicali, 145; Nogales, 63; Matamoros, 78 y Agua Prieta, 36 (véase NNEGI, Avance de información económica. Industria maquiladora de exportación, marzo de 1989, cuadro 12, p. 28). 
CUADRO 3. Plantas maquiladoras de la zona fronteriza norte $y$ proporción que representan en el empleo, el valor agregado y en salarios y prestaciones de la maquila en México, 1973-1988.

\begin{tabular}{llcccc}
\hline Afto & $\begin{array}{c}\text { Total } \\
\text { Nacional }\end{array}$ & $\begin{array}{c}\text { Número de } \\
\text { plantas }\end{array}$ & $\begin{array}{c}\text { Empleos } \\
\text { generados }\end{array}$ & $\begin{array}{c}\text { Valor } \\
\text { agregado }\end{array}$ & $\begin{array}{c}\text { Salarios y } \\
\text { prestaciones }\end{array}$ \\
\hline 1973 & 100.0 & 96.1 & 93.5 & 90.1 & 93.2 \\
1974 & 100.0 & 94.3 & 93.6 & 91.6 & 93.2 \\
1975 & 100.0 & 92.1 & 92.5 & 90.3 & 92.6 \\
1976 & 100.0 & 90.1 & 90.6 & 89.3 & 92.7 \\
1977 & 100.0 & 89.9 & 90.1 & 87.7 & 91.8 \\
1978 & 100.0 & 91.9 & 90.8 & 88.1 & 92.1 \\
1979 & 100.0 & 88.9 & 90.3 & 84.6 & 91.4 \\
1980 & 100.0 & 88.9 & 89.1 & 85.8 & 90.6 \\
1981 & 100.0 & 88.1 & 88.9 & 86.5 & 89.9 \\
1982 & 100.0 & 87.1 & 89.1 & 86.7 & 90.3 \\
1983 & 100.0 & 88.8 & 89.4 & 87.1 & 90.6 \\
1984 & 100.0 & 93.9 & 95.4 & 92.8 & 95.4 \\
1985 & 100.0 & 94.0 & 95.5 & 92.2 & 94.5 \\
1986 & 100.0 & 92.7 & 95.3 & 92.2 & 96.3 \\
1987 & 100.0 & 90.5 & 93.8 & 91.4 & 94.4 \\
1988 & 100.0 & 89.5 & 92.6 & 90.3 & 93.4 \\
& & & & & \\
\hline
\end{tabular}

vUENTE: 1973-1983, calculado de Joseph Grunwald y Kenneth Flamm, op. cit., cuadros 4-1 y 4-2, pp. 140 y 143. 1984-1988, calculado de INEGI, op. cit., (cifras en pesos mexicanos) y Banco de México, op. cit., (cifras de tipo de cambio).

tipo de productos que producen son los que implican fuertes costos de transporte. En 1980, los tres principales productos de las maquiladoras do la frontera, tanto en términos del personal ocupado como del valor agregado y del número de establecimientos, fueron: 1) los materiales y accesorios electricos y electrónicos, 2) el ensamble de maquinaria, aparatos y artículos oléctricos y electrónicos, y 3) el ensamble de prendas de vestir y otros productos confeccionados con textiles y otros materiales. Estos tres productos juntos representaron ese año el $71.5 \%$ del personal ocupado, el $67.0 \%$ del valor agregado y el $53.3 \%$ de los establecimientos de las maquiladoras establecidas en la frontera norte de México. En 1985, la estructura de la industria en términos del tipo de productos mostró una mayor diversificación que en 1980: los tres productos principales repre- 
sentaron el $67.0 \%$ del personal ocupado y el $49.2 \%$ de los establecimientos. Sin embargo, el surgimiento de partes automotrices como el producto más importante en cuanto al valor agregado llevó la participación de los tres productos principales al $71.1 \%$ del valor agregado total en ese año (INEGI, 1986).

\section{Los impactos sociodemográficos y tecnológicos de la industria}

Desde su inicio, el programa mexicano de maquiladoras ha originado en México un debate en cuanto a las ventajas o desventajas que representa para la sociedad mexicana y para sus posibilidades futuras de desarrollo. Las áreas de este debate tienen que ver principalmente con los impactos demográficos que la estructura organizacional y la operación real de las empresas maquiladoras tiene al través de sus efectos en la estructura del empleo (por sexo, edad, estado civil y escolaridad), el aprendizaje y el adiestramiento de los trabajadores, y en la transferencia de tecnología que representan. Igualmente importante es el tema de su integración a la economía nacional.

\section{Los impactos en la estructura del empleo}

Por regla general, las maquiladoras realizan procesos de producción intensivos en el uso de la mano de obra. Los datos oficiales muestran que entre 1979 y 1985, las maquiladoras de México emplearon cerca de tres veces más mujeres que hombres como obreros; sin embargo, los datos sugieren que las maquiladoras de la frontera tienen una ligera tendencia a contratar relativamente más hombres que las del resto del país. Por otro lado, los datos también muestran una tendencia general de las maquiladoras a emplear cada vez mayores proporciones de hombres como obreros. Por ejemplo, mientras que en 1979 el $22.5 \%$ de los obreros contratados a nivel nacional eran hombres, la proporción correspondiente en la frontera fue de $23.4 \%$, para 1985 los hombres representaron el $30.9 \%$ de los obreros contratados por la industria a nivel nacional y el $32.8 \%$ en el caso de la frontera (INEGI, 1986).

Es importante mencionar que la información disponible sobre el tipo de mano de obra usada en actividades de ensamble en países desarrollados indica características semejantes a las maquiladoras de México, lo que hace pensar que la aparente selectividad de éstas tiene que ver fundamentalmente con la función de producción. Según Grunwald y Flamm, (1985:168) "la preponderancia de mujeres en las actividades de ensamble parece ser

universal y no exclusiva de países en desarrollo. La proporción en Estados Unidos parece ser más alta que en México, con un promedio de $90 \% . . . "$. 
En têrminos de la edad, la estructura del empleo de las maquiladoras sugiere una tendencia clara hacia los trabajadores jóvenes. La información disponible muestra que, aunque la estructura ha cambiado recientemente, la gran mayoría de los trabajadores de las maquiladoras en la frontera se encuentran entre los 16 y los 25 afios de edad (Grunwald Flamm, 1985:168).

Además de mano de obra joven y femenina, la maquiladoras en México muestran una tendencia a contratar trabajadores solteros. En 1979, las empresas localizadas en la frontera norte del país contrataron en su mayoría solteros. Información de trabajo de campo muestra que alrededor del $60 \%$ de las mujeres que trabajan en esas maquiladoras ese año eran solteras, y aunque la proporción correspondiente a los hombres era solamente de $37.8 \%$, hubo ramas de actividad donde la proporción alcanz $\delta$ valores considerables, como la de los metales primarios, donde la proporción de mujeres solteras fue de $100 \%$ y la de hombres solteros, $62.5 \% .^{5}$

La información sobre el nivel de escolaridad de los trabajadores de las maquiladoras de la zona fronteriza sugiere "una preferencia de los gerentes de las plantas maquiladoras por contratar mano de obra con cierto nivel de escolaridad". 6 Esto es explicado en términos de que un nivel medio de escolaridad "asegura el buen cumplimiento de la tarea asignada y la capacidad del trabajador para soportar ocho horas de trabajo monótono y meticuloso en la línea de ensamble... [así como]...una tasa baja de rotación de la mano de obra" (Fernández y Buen, 1984:354).

Se ha argumentado que la selección de mano de obra femenina joven es una práctica común de los administradores de las maquiladoras que buscan mano de obra dócil, ya que las mujeres jóvenes, por ser en su mayoría solteras y no haber formado previamente parte de la fuerza de trabajo, no son muy propensas a formar parte de organizaciones sindicales ni a establecer litigios contra las empresas. Sin embargo, e independientemente de si se debe a prácticas discriminatorias o no, el hecho es que en elevada proporción la mano de obra empleada en las maquiladoras en México es femenina, joven, sin fuertes compromisos familiares y sin haber formado parte previamente de la fuerza de trabajo.

5 Esta selectividad en ocasiones es explicada simplemente como una práctica sesgada de los empresarios maquiladores. Por ejemplo, Donald Bearrasen, en The Border Industrializacion Program of Mexico p. 35 (Bearrasen 1973), afirma que "La mayoría de los gerentes de las plantas maquiladoras prefieren emplear mujeres solteras".

6 Encuesta nacional a plantas maquiladoras, realizada por el Centro de Investigación y Docencia Económica entre maquiladoras de la frontera norte de México en septiembre de 1979, reportada por José Luis Femández y Bertha Elena de Buen (1984:340-368). 
Los impactos en el aprendizaje, el adiestramiento y la transferencia de tecnologia

Además de los efectos en los niveles y las categorías del empleo, en México se han debatido los efectos de las maquiladoras en la calificación de la mano de obra que utilizan. Se supone que por ser actividades nuevas, los empleados de las maquiladoras ganarán conocimiento en los procesos de producción y de las técnicas administrativas, como parte del entrenamiento que reciben en las plantas. Los efectos en la calificación de mano de obra : pueden detectarse al través de los puestos desempeñados en la planta, del nivel de escolaridad de los empleados y del entrenamiento recibido.

La mayor parte de los empleados en las maquiladoras en México entre 1975 y 1985 han sido obreros, y aunque con el tiempo se han contratado más técnicos de producción y más empleados administrativos, la proporción de obreros no ha bajado del 80\% (INEGI, 1986). Por otro lado, en 1979 más de la mitad de los trabajadores de las maquiladoras fronterizas habfan realizado solamente una semana o menos de entrenamiento, independientemente de si eran obreros, técnicos de producción o empleados administrativos (Fernández y Buen, 1984:363).

Más recientemente, en un estudio efectuado en 1985 entre 42 empresas maquiladoras en México, se encontró que "la gran mayoría de las empresas maquiladoras... realizan actividades de capacitación de su personal" (Martínez del Campo, 1986:34). Dicha capacitación varía según el tipo de empresa y el puesto desempefiado por el empleado, pero "en general, podría asentarse que el nivel en que se realiza... [el adiestramiento]... dentro de la industria maquiladora de exportación... es mucho más elevado que el que se imparte en las empresas nacionales" (Martínez del Campo, 1986:34).

Además de los niveles de calificación y adiestramiento de su personal, el debate sobre los efectos de las maquiladoras ha incluido el tema específico de la transferencia de tecnología que se espera mejore, entre otras cosas, la productividad de los trabajadores. Sin embargo, y no obstante la importancia del tema, hasta muy recientemente los estudios sobre maquiladoras sólo cubrían aspectos de calificación y adiestramiento de la mano de obra y destacaban la sencillez tecnológica de los procesos de ensamble. ${ }^{7}$

Los resultados de un estudio reciente, muestran que el $66 \%$ de los técnicos medios e ingenieros que ingresan a las maquiladoras proviene

7 Por ejemplo, Sergio Rivas F. (1985:1075) identifica el 14\% de las maquiladoras en México con complejidad tecnológica media y el $38 \%$ con complejidad tecnológica alta, de acuerdo con los criterios del Programa Nacional de Fomento a las Importaciones y al Comercio Exterior. Además, por los mismos criterios, preve que no habrá cambios radicales en la complejidad tecnologica de esas ramas entre 1984 y 2000 (sic). 
directamente de las escuelas; otro $25 \%$ proviene de otras maquiladoras, y otro $9 \%$ proviene de la industria nacional. Asimismo muestran que el $62 \%$ del personal correspondiente que sale de las maquiladoras tiene por destino otras maquiladoras; otro $21 \%$ va a la industria nacional, y otro $17 \%$ a ocupaciones diversas. Esto muestra que el flujo de personal técnico es mayor en la dirección sector nacional-maquiladoras (75\%) que en la dirección maquiladoras-sector nacional (38\%), lo que puede deberse a las menores posibilidades de empleo de la industria nacional en las áreas geográficas en las que se hizo la encuesta (Martínez del Campo, 1986:30).

\section{Integración de la economía interna}

La integración de las maquiladoras a la economía nacional tiene que ver con el origen de las compras y el destino, tanto de las ventas como de los ingresos generados directa e indirectamente por sus operaciones. En cuanto al origen de las compras de materias primas, envases y empaque, las maquiladoras importan en términos generales proporciones bastante elevadas de sus insumos, y esta práctica no ha cambiado mucho por lo menos entre 1975 y 1986. (véase cuadro 4). Por otro lado, se ha estimado que "durante el período 1975-1986, por cada peso generado en forma directa..[por las maquiladoras]... en la economía mexicana, en Estados Unidos se generan tres" (Rivas F., 1985:1079).

La información disponible permite también inferir que las maquiladoras establecidas en la región fronteriza del norte de México adquieren insumos mexicanos (aparte de los localizados) en menor proporción que las ubicadas en el resto del país. Entre 1975 y 1986, las maquiladoras fronterizas adquirieron un promedio anual del $1.10 \%$ de sus insumos en México; la cifra para las ubicadas en el resto del país fue de $8.40 \%$ (véase cuadro 4).

En cuanto al destino de las ventas, a partir de agosto de 1983 se autorizó a las maquiladoras la venta hasta un máximo del $20 \%$ de su producción (en condiciones decididas caso por caso por el gobierno federal) en el mercado nacional. Según información oficial, durante 1985 el gobierno mexicano autorizo vender en el mercado nacional a 15 de 21 empresas maquiladoras que solicitaron hacerlo. Entre enero y julio de 1985, se autorizo a 28 de 44 empresas que lo solicitaron (Véase María y Campos, 1986:22).

$8 \mathrm{El}$ autor reconoce que entre el personal administrativo existe mayor intercambio entre maquiladoras, así como entre maquiladoras y otras actividades. Sin embargo, ese resultado no sobresale porque los números absolutos son bastante reducidos en esos casos (p. 32). 
CUADRO 4. México: Estructura relativa de las compras de insumos por la industria maquiladora, 1975-1985 (porcentajes).

\begin{tabular}{|c|c|c|c|c|c|}
\hline Afno & $\begin{array}{l}\text { Insumos } \\
\text { totales } \\
(a)=(b, c)\end{array}$ & $\begin{array}{l}\text { Insumos } \\
\text { importados } \\
\text { (b) }\end{array}$ & $\begin{array}{l}\text { Insumos } \\
\text { nales. } \\
\text { (c) }\end{array}$ & $\begin{array}{c}\text { Insumos n } \\
\text { Plantas en } \\
\text { frontera } \\
\text { (d) }\end{array}$ & $\begin{array}{l}\text { racionales en: } \\
\text { Plantas en el } \\
\text { resto del país } \\
\text { (e) }\end{array}$ \\
\hline 1975 & 100.0 & 98.6 & 1.4 & 0.8 & 9.9 \\
\hline 1976 & 100.0 & 97.0 & 3.0 & 2.1 & 15.4 \\
\hline 1977 & 100.0 & 98.5 & 1.5 & 1.6 & 6.1 \\
\hline 1978 & 100.0 & 98.2 & 1.8 & 1.0 & 6.9 \\
\hline 1979 & 100.0 & 98.6 & 1.4 & 0.9 & 7.9 \\
\hline 1980 & 100.0 & 98.3 & 1.7 & 0.8 & 10.0 \\
\hline 1981 & 100.0 & 98.7 & 1.3 & 0.8 & 7.1 \\
\hline 1982 & 100.0 & 98.7 & 1.3 & 0.8 & 6.9 \\
\hline 1983 & 100.0 & 98.7 & 1.3 & 1.0 & 4.4 \\
\hline 1984 & 100.0 & 98.7 & 1.3 & 1.1 & 8.6 \\
\hline 1985 & 100.0 & 99.1 & 0.9 & 0.7 & 7.3 \\
\hline 1986 & 100.0 & 98.8 & 1.2 & 0.8 & 9.0 \\
\hline 1987 & 100.0 & 98.5 & 1.5 & 1.0 & 14.9 \\
\hline 1988 & 100.0 & 98.3 & 1.7 & 1.1 & 13.4 \\
\hline Promedio & 100.0 & 98.5 & 1.5 & 1.1 & 10.4 \\
\hline
\end{tabular}

FUENTE: 1975-1983, calculado de Joseph Grunwald y Kenneth Flamm, op. cit., cuadro 4-14, p. 162; 1984-1988, INEGI, Avance de información económica. Industria maquiladora de exportación, mayo de 1987, cuadro 5 y marzo de 1989, cuadro 5.

Referente al destino de los ingresos generados en México por las maquiladoras, se ha argumentado que "cuando menos $50 \%$ del valor de los sueldos y salarios pagados en las empresas maquildoras ubicadas en la frontera norte del país...se remite a Estados Unidos en forma de compras de ropa y alimentos" (Rivas F., 1985:1079).

Por la existencia de zonas libres en la frontera y la propia yuxtaposición de las ciudades fronterizas, se infiere que esas fugas son bastante menores en el caso de las maquiladoras del resto del país.

\section{Reflexiones generales}

El análisis anterior indica que la información disponible sugiere que la industria maquiladora en México, tal como se ha establecido hasta ahora 
en forma predominante en la zona fronteriza norte, tiene todavfa las características de un enclave; es decir, de una actividad económica que, si bien emplea trabajadores nacionales y genera exportación de valor agregado, no se integra ni a la economía regional ni a la nacional. Por otro lado, la forma tan sesgada en que las empresas maquiladoras emplean mano de obra predominantemente femenina joven, de bajo nivel de educación y escasa calificación - solteras que no formaban parte de la fuerza de trabajo antes de ingresar a trabajar en las plantas- asi como los niveles tan bajos de capacitación y adiestramiento que ofrecen las empresas a sus trabajadores, apuntan a que la maquila no ha alcanzado cabalmente los objetivos que le fueron asignados, entre los que destacan el de iniciar y estimular un proceso de industrialización y generación de empleo en una región (la fronteriza) orientada a los servicios y desvinculada de la economía nacional, y el de promover el bienestar general de los trabajadores.

En la siguiente sección se describen las características de la encuesta COSIMCED, dirigida por el autor, cuyos objetivos incluyeron los de detectar los impactos de la maquila en el empleo, los ingresos y el bienestar familiar de los trabajadores, y conocer la apreciación de líderes locales de opinión en cuanto a los impactos más generales de las maquiladoras en las condiciones de vida de las localidades y regiones donde operan.

\section{LA ENCUESTA COSIMCED}

Como se mencionó en la introducción, el principal objetivo de este trabajo es el de presentar algunos resultados de un estudio patrocinado por la Comisión para el Estudio de la Migración Internacional y la Cooperación para el Desarrollo Económico del Congreso de los Estados Unidos de Norteamérica (COSIMCED). Dicho estudio está basado, fundamentalmente, en tres encuestas realizadas durante finales de 1988 y principios de 1989 en tres ciudades fronterizas del norte de México y una del interior del país.

Una de las encuestas se levantó entre trabajadores de las maquiladoras de las ciudades fronterizas de Tijuana, Ciudad Juárez y Nuevo Laredo, y de la ciudad no fronteriza de Guadalajara, con una muestra de 300 trabajadores en cada una. Otra de las encuestas se levantó entre empresarios maquiladores de plantas localizadas en las cuatro ciudades mencionadas, con una muestra total de 40 empresarios ( 10 por ciudad). La otra, se levantó entre líderes de opinión de las ciudades estudiadas, incluidos académicos, líderes obreros, representantes industriales y comerciantes, así como funcionarios municipales, estatales y/o federales, entre otros, considerando una muestra total de 40 individuos ( 10 por ciudad). 
En esta sección, se describen los objetivos, la metodología y algunos resultados de la encuesta a trabajadores maquiladores, dejando para después lo referente a la encuesta a líderes de opinión.

\section{Objetivos}

No obstante que uno de los objetivos principales de la COSIMCED es el de investigar las posibles causas de migración de mexicanos a Estados Unidos, se optó por realizar una encuesta que al mismo tiempo que detectara el impacto actual de la industria maquiladora en los movimientos migratorios (internos e internacionales) de los mexicanos, permitiera también evaluar el impacto que la industria tiene en las condiciones generales de vida de las localidades donde operan, así como la evolución de su estructura laboral.

\section{Metodología}

Por lo anterior, se diseńo una metodología general cuyos elementos fundamentales fueron: a) considerar como objetivo los trabajadores de empresas maquiladoras localizadas en ciudades fronterizas y no fronterizas, ya que las cifras oficiales y los estudios de campo sugieren diferencias importantes en su operación; b) seleccionar ciudades que, al mismo tiempo que contrastaran en términos de ser sedes importantes de plantas maquiladoras, tuvieran también antecedentes recientes e importantes de migración de trabajadores, y c) estructurar una muestra de trabajadores, compuesta por migrantes y no migrantes, para poder comparar características y comportamientos, y que además considerara como variable de control el sexo, ya que una de las grandes diferencias entre la maquila y el resto de la industria en México está precisamente en esa variable.

Se seleccionaron asi las ciudades fronterizas de Tijuana, Ciudad Juárez y Nuevo Laredo y la no fronteriza de Guadalajara, ya que en enero de 1989 Tijuana alojaba al $26.3 \%$ del total de plantas maquiladoras del país, mientras que en Ciudad Juárez se empleaba al $29.7 \%$ de los trabajadores de la industria y se generaba el $31 \%$ de su valor agregado total. Juntas, esas ciudades representaban, en enero de 1989 , el $43 \%$ de la industria maquiladora en términos del número de establecimientos; el $43 \%$ en términos de personal ocupado, y el $45 \%$, en términos de valor agregado. Por otro lado, Nuevo Laredo en 1986 solamente tenía al $2 \%$ de los establecimientos y el 1.8\% de los trabajadores de la industria, mientras que generaba el $1.7 \%$ de su valor agregado, siendo en esos aspectos la ciudad fronteriza con el menor (o el segundo menor) grado de participación en la industria, de acuerdo con los datos 
CUADRO 5. Estructura relativa del número de establecimientos. Personal ocupado y valor agregado de la industria maquiladora, por municipio, 1986 y 1989.

\begin{tabular}{lrrrrrr}
\hline & \multicolumn{2}{c}{$\begin{array}{c}\text { Número de } \\
\text { Municipio }\end{array}$} & \multicolumn{2}{c}{$\begin{array}{c}\text { Personal } \\
\text { establecimientos }\end{array}$} & \multicolumn{2}{c}{$\begin{array}{c}\text { Valor agregado } \\
\text { (mill. de pesos) }\end{array}$} \\
& 1986 & 1989 & 1986 & 1989 & 1986 & 1989 \\
\hline & & & & & & \\
Total Nacional & 891 & 1518 & 249833 & 393658 & 385420 & 476741 \\
(\%) & 100.0 & 100.0 & 100.0 & 100.0 & 100.0 & 100.0 \\
& & & & & & \\
Tijuana & 25.3 & 26.3 & 12.2 & 13.0 & 12.1 & 13.2 \\
Cd. Juárez & 22.1 & 16.7 & 36.6 & 29.7 & 38.5 & 31.8 \\
Nvo. Laredo & 2.0 & n.d. & 1.7 & n.d. & 1.7 & n.d. \\
Mexicali & 9.9 & 9.5 & 5.1 & 5.2 & 5.5 & 5.9 \\
Tecate & 4.1 & n.d. & 1.2 & n.d. & 1.4 & n.d. \\
Cd. Acuria & 3.2 & n.d. & 3.0 & n.d. & 2.1 & n.d. \\
P. Negras & 2.4 & n.d. & 2.1 & n.d. & 1.6 & n.d. \\
Agua Prieta & 3.2 & n.d. & 2.7 & n.d. & 1.8 & n.d. \\
Nogales & 6.4 & 4.1 & 6.8 & 5.7 & 6.0 & 5.0 \\
Matamoros & 4.6 & 5.1 & 9.8 & 9.0 & 11.9 & 10.3 \\
Reynosa & 3.5 & n.d. & 6.0 & n.d. & 4.8 & n.d. \\
Otros & 13.3 & 38.3 & 12.8 & 37.4 & 12.6 & 33.8 \\
& & & & & & \\
\hline
\end{tabular}

FURNTE: Los datos de 1986, provienen de INEGI, Estadística de la industria maquiladora de exportación 1975-1986, op.cit. Cuadro 1, p. 1; los de 1989 de INEGI, Avances de información económica. Industria maquiladora de exportación, marzo de 1989, Cuadro 12, p. 28.

oficiales disponibles (ver cuadro 5). La ciudad de Guadalajara fue seleccionada para el estudio por su localización geográfica (en un estado no fronterizo).

Operacionalmente, se decidió tomar una muestra de 300 trabajadores maquiladores por ciudad, lo que conformó una muestra global de 1,200 trabajadores para el estudio, cifra que es más o menos comparable con las más amplias y significativas consideraciones en estudios anteriores. Por los objetivos del estudio, y a falta de información oficial sobre la estructura laboral por condición de residencia en las maquiladoras, se decidió estructurar la muestra con un número igual de migrantes y no migrantes, pero se decidió mantener una estructura por sexo semejante a la de las cifras oficiales promedio para la industria a nivel nacional en 1988: $37.5 \%$ hombres y $62.5 \%$ mujeres. En otras palabras, la muestra global estuvo 
compuesta, por un lado, por 600 trabajadores migrantes y por 600 no migrantes, y por otro, por 755 mujeres y 445 hombres.

El cuestionario usado en la encuesta incluía las preguntas que, entre otras cosas, permitian conocer los datos generales del trabajador, tales como lugar de nacimiento, sexo, edad, estado civil, alfabetismo, tamafio y estructura por sexo y dependencia económica de su familia y su nivel de escolaridad, así como las características del empleo del trabajador en las maquiladoras, tanto previas como al momento de la entrevista, además de las características de la capacitación recibida en la industria, la importancia del ingreso recibido en las maquiladoras en las finanzas domésticas y la evaluación del trabajador en cuanto al impacto de su empleo en las maquiladoras en el bienestar de su familia.

Después de ser probados en campo y corregidos definitivamente, dichos cuestionarios fueron aplicados por entrevistadores con un nivel de escolaridad universitaria como mínimo, siguiendo esta mecánica: a) seleccionar aleatoriamente 10 empresas maquiladoras en cada una de las ciudades, a partir de las listas que han sido publicadas; b) ubicarse físicamente en las maquiladoras seleccionadas y esperar la salida de los trabajadores para entrevistarlos; c) entrevistar a los trabajadores en forma aleatoria, hasta completar la cuota por planta de 15 trabajadores migrantes y 15 no migrantes, - a partir de preguntar donde había nacido- por un lado, y de 18-19 mujeres y 11-12 hombres, por otro, a partir de la observación directa; d) en caso de rechazo, anotarlo y proseguir entrevistando a otro prospecto. La encuesta se inició en diciembre de 1988 y se concluyó en enero de 1989.

\section{Resultados principales}

En esta parte se presentan los resultados más importantes de la encuesta, destacando las diferencias entre ciudades y entre hombres y mujeres que tienen que ver con las características generales de los entrevistados (en términos de edad, estado civil, escolaridad y estructura familiar) y con las características de su empleo en las maquiladoras, dejando para la sección siguiente aquéllas relacionadas directamente con los objetivos específicos del trabajo, es decir, las que tratan de los impactos de las maquiladoras en el bienestar familiar y en las condiciones de vida de la comunidad.

\section{Características generales de los entrevistados}

Independientemente de su calidad migratoria, la fuerza laboral de las maquiladoras es predominantemente joven: cerca del $80 \%$ de los trabaja- 
dores tienen menos de 25 años de edad. En el cuadro 6 se muestra que entre las ciudades fronterizas, la estructura laboral tiende a ser más joven que on la no fronteriza de Guadalajara, donde no solamente se tienen trabajadores de casi todas las edades, sino que es el único lugar donde el grupo de edad de 15- 19 años no fue el más numeroso.

CUADRO 6. Trabajadores en las maquiladoras según ciudad y grupos de edad.

\begin{tabular}{|c|c|c|c|c|c|c|c|c|c|c|}
\hline \multirow{2}{*}{$\begin{array}{l}\text { Grupos de edad } \\
\text { (años) }\end{array}$} & \multicolumn{2}{|c|}{ Cd. Juárez } & \multicolumn{2}{|c|}{ Nvo. Laredo } & \multicolumn{2}{|c|}{ Tijuana } & \multicolumn{2}{|c|}{ Guadalajara } & \multicolumn{2}{|c|}{ Total de cds. } \\
\hline & ABS & $\%$ & ABS & $\%$ & $\mathrm{ABS}$ & $\%$ & ABS & $\%$ & ABS & $\%$ \\
\hline 5 a 19 & 121 & 40.3 & 169 & 56.3 & 148 & 49.3 & 104 & 34.7 & 542 & 45.2 \\
\hline $20 \mathrm{a}$ & 103 & 34.3 & 90 & 30.0 & 98 & 32.7 & 112 & 37.3 & 403 & 33.6 \\
\hline 5 a & 43 & 14.3 & 20 & 6.7 & 30 & 10.0 & 41 & 13.7 & 134 & 11.2 \\
\hline o a & 14 & 4.7 & 10 & 3. & 14 & 4.7 & 17 & 5.7 & 55 & 4 \\
\hline 5 a & 12 & 4.0 & 5 & 1.7 & 7 & 2.3 & 16 & 5.3 & 40 & 3. \\
\hline 40 a 44 & 6 & 2.0 & 5 & 1.7 & 3 & 1.0 & 4 & 1.3 & 18 & 1. \\
\hline 45 a 45 & & & & & & & 3 & 1.0 & 3 & 0. \\
\hline 50 y más & & & & & & & 3 & 1.0 & 3 & 0.3 \\
\hline No especificada & 1 & 0.3 & 1 & 0.3 & & & & & 2 & 0.2 \\
\hline Total & 300 & 100.0 & 300 & 100.0 & 300 & 100.0 & 300 & 100.0 & 1200 & 100.0 \\
\hline
\end{tabular}

FUENTE: Encuesta COSIMCED.

En términos del estado civil, la soltería fue la más común entre los individuos de la muestra. Más del $72 \%$ de la fuerza laboral entrevistada tenían ese estado civil al momento de la encuesta.

Es importante destacar, sin embargo, algunas diferencias importantes en la estructura de la muestra por estado civil y sexo, atribuibles a la influencia de la localización geográfica. En el cuadro 7 se muestra que la localidad de Guadalajara es la responsable principal de que entre el sexo femenino de la muestra a nivel global se encuentre el más alto porcentaje de solteros. Ahí el $\mathbf{8 0 . 2 \%}$ de las mujeres entrevistadas eran solteras, y sólo el $52.8 \%$ de los hombres lo eran. De hecho, la estructura de Guadalajara y la de Ciudad Juárez, donde las cifras respectivas fueron $73.6 \%$ y $64.8 \%$, juntas compensan las de Nuevo Laredo y Tijuana donde la estructura es, incluso, inversa a la de la muestra global.

Las características de la muestra global, en términos de escolaridad, sugieren cierta homogeneidad en el nivel de escolaridad de los trabajadores 
entre las cuatro ciudades estudiadas. Por ejemplo, solamente en Ciudad Juárez más del $20 \%$ de los entrevistados tenían estudios de nivel más alto que el primario y la diferencia con las demás ciudades no rebasó el $5 \%$. CUADRO 7. Trabajadores en las maquiladoras según ciudad, sexo
y estado civil.

\begin{tabular}{|c|c|c|c|c|c|}
\hline Edo. civil & $\begin{array}{r}\text { Casado } \\
\text { Abs. } \%\end{array}$ & $\begin{array}{l}\text { Soltero } \\
\text { Abs. \% }\end{array}$ & $\begin{array}{l}\text { Viudo Divorciado } \\
\text { Abs. } \% \text { Abs. } \%\end{array}$ & $\begin{array}{l}\text { U. Libre } \\
\text { Abs. } \%\end{array}$ & $\begin{array}{c}\text { Total } \\
\text { Abs. } \%\end{array}$ \\
\hline
\end{tabular}

\section{Cd. Juárez}

Mas. $\begin{array}{llll}39 & 32.0 & 79 & 64.8\end{array}$

21.6

$\begin{array}{lllll}2 & 1.6 & 122 & 100.0\end{array}$

Fem.

$\begin{array}{llll}34 & 19.1 & 131 & 73.6\end{array}$

10.6 .52 .8

$\begin{array}{llll}7 & 3.9 & 178 & 100.0\end{array}$

Nvo. Laredo

Mas.

$\begin{array}{llll}22 & 21.2 & 81 & 77.9\end{array}$

$\begin{array}{llll}1 & 1.0 & 104 & 100.0\end{array}$

Fem.

$\begin{array}{llll}38 & 19.4 & 152 & 77.6\end{array}$

$\begin{array}{llll}1 & 0.5 & 3 & 1.5\end{array}$

$\begin{array}{llll}2 & 1.0 & 196 & 100.0\end{array}$

Tijuana

Mas.

$\begin{array}{llll}21 & 18.9 & 86 & 77.5\end{array}$

Fem.

$\begin{array}{llll}49 & 25.9 & 130 & 68.8\end{array}$

$\begin{array}{llll}3 & 1.6 & 2 & 1.1\end{array}$

$\begin{array}{llll}4 & 3.6 & 111 & 100.0\end{array}$

$\begin{array}{llll}5 & 2.6 & 189 & 100.0\end{array}$

Guadalajara

Mas.

$\begin{array}{llll}48 & 44.4 & 57 & 52.8\end{array}$

Fem.

$\begin{array}{lllll}33 & 17.2 & 154 & 80.2\end{array}$

$\begin{array}{llll}1 & 0.5 & 4 & 2.1\end{array}$

$\begin{array}{llll}3 & 2.8 & 108 & 100.0\end{array}$

192100.0

Total de Cds.

$\begin{array}{lllllllrlllll}\text { Mas. } & 130 & 29.2 & 303 & 68.1 & & & 2 & 0.4 & 10 & 2.2 & 445 & 100.0 \\ \text { Fem. } & 154 & 20.6 & 567 & 75.1 & 6 & 0.8 & 14 & 1.9 & 14 & 1.9 & 755 & 100.0\end{array}$

FUENTE: Encuenta COSIMCED.

En términos de la influencia del sexo en la estructura por escolaridad de la muestra, se encontraron niveles más elevados de escolaridad entre el sexo masculino, donde el $24 \%$ de los trabajadores tenf́an niveles más altos que el primario, comparado con el $17 \%$ que era la cifra correspondiente al sexo femenino. Por otro lado, las diferencias mayores de escolaridad entre hombres y mujeres se encontraron en las ciudades de Juárez y Tijuana, donde el número de trabajadores hombres con escolaridad más alta que el nivel primario representaban el $29.6 \%$ y el $26.1 \%$, mientras que el correspondiente a las mujeres era de $17.4 \%$ y $16.4 \%$, respectivamente (cuadro 8 ).

En resumen, puede decirse que, no obstante algunas variaciones hacia adentro de la muestra, la fuerza laboral de las maquiladoras es predominantemente joven, soltera y con niveles de estudios relativamente altos. 
CUADRO 8. Trabajadores en las maquiladoras según ciudad, sexo y nivel de escolaridad.

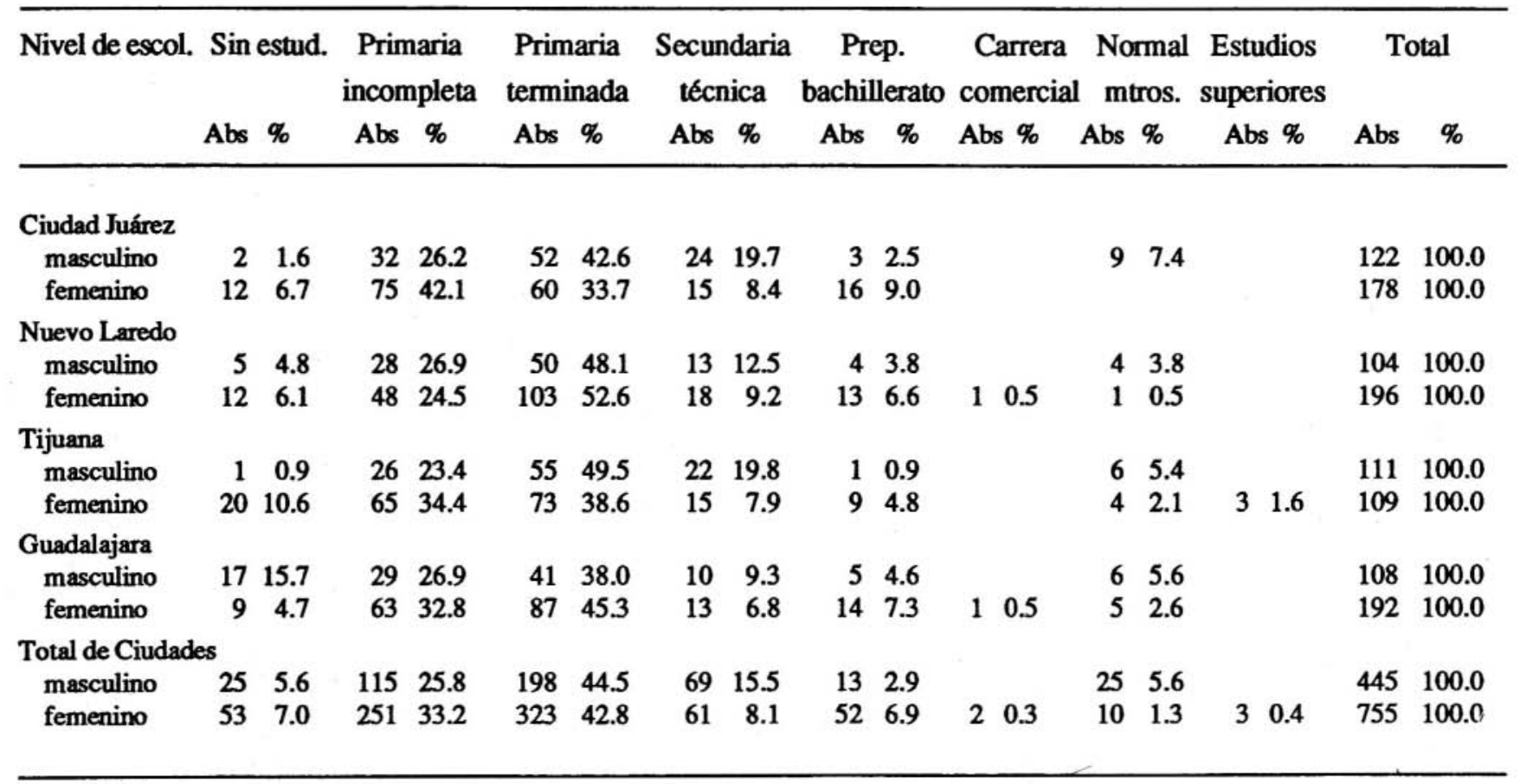

FUENTE: Encuesta COSIMCED. 
Por otro lado, puede decirse que las variaciones más importantes se dieron como sigue: eran más jóvenes las trabajadoras mujeres y los residentes de las ciudades fronterizas; mayormente solteras las trabajadoras mujeres, y los residentes de algunas ciudades fronterizas; y con niveles más altos de escolaridad los trabajadores hombres y los residentes de ciudades fronterizas.

\section{Características del empleo y la capacitación de los estrevistados}

Los resultados de la encuesta a trabajadores maquiladores muestran que la mayoría de los entrevistados (53.8\%) habían estado sin empleo antes de involucrarse en la maquiladora en que trabajaban al momento de la entrevista, y que la voluntad propia (y no el despido) había sido el motivo principal para cambiar de trabajo en el $34.5 \%$ de los casos de quienes sí tenían empleo previo al de la maquiladora donde trabajaban al momento de la encuesta.

No obstante lo anterior, se encontró una diferencia importante entre las ciudades de la frontera y la ciudad no fronteriza de Guadalajara en cuanto al empleo previo de los trabajadores maquiladores: en la ciudad no fronteriza, la mayoría de los entrevistados $(58.7 \%)$ sí tenían empleo previo.

Por otro lado, los resultados de las preguntas sobre la capacitación recibida por los trabajadores en las maquiladoras indican que la mayoría de los trabajadores no recibían capacitación, y cuando lo hacían, ésta duraba por lo regular menos de una semana, encontrándose diferencias importantes entre localidades. En el cuadro 9 se muestra que la proporción

CUADRO 9. Trabajadores en las maquiladoras según ciudad y duración del entrenamiento recibido a su ingreso a las maquiladoras.

Tiempo de capacitación

Cd. Juárez Nvo. Laredo Tijuana

Guadalajara Total de cds. Abs. $\%$ Abs. $\%$ Abs. $\%$ Abs. $\%$ Abs. $\%$

\begin{tabular}{|c|c|c|c|c|c|c|c|c|c|c|}
\hline Sin capacitación & 186 & 62.0 & 118 & 39.3 & 138 & 46.0 & 176 & 58.7 & 618 & 51 \\
\hline De 1 a 5 días & 57 & 19.0 & 109 & 36.3 & 100 & 33.3 & 49 & 16.3 & 315 & \\
\hline De 6 a 10 días & 16 & 5.3 & 19 & 6.3 & 15 & 5.0 & 35 & 11.7 & 85 & \\
\hline De 11 a 15 días & 10 & 3.3 & 24 & 8.0 & 22 & 7.3 & 11 & 3.7 & 67 & \\
\hline De 16 a 20 días & 13 & 4.3 & 14 & 4.7 & 14 & 4.7 & 11 & 3.7 & 52 & \\
\hline Más de 20 días & 17 & 5.7 & 16 & 5.3 & 11 & 3.7 & 17 & 5.7 & 61 & \\
\hline No especificado & 1 & 0.3 & & & & & 1 & 0.3 & 2 & \\
\hline Total & 300 & 100.0 & 300 & 00.0 & 300 & 100.0 & 300 & 100.0 & 1200 & 00 \\
\hline
\end{tabular}

FUENTE: Encuesta COSIMCED 
de los trabajadores que no recibieron ningún tipo de capacitación varió entre el 39.3\% (en Nuevo Laredo) y el 62.0\% (en Ciudad Juárez), mientras que la de los que recibieron más de 5 días de capacitación varió entre el $18.6 \%$ (en Ciudad Juárez) y el 24.8\% (en Guadalajara).

\section{Reflexiones generales}

Las características generales de los trabajadores maquiladores entrevistados concuerdan, básicamente, con las observadas en otros estudios y con las que sugieren los datos publicados. La estructura de la mano de obra en las maquiladoras aunque ha cambiado recientemente, sigue siendo dominada por gente joven, soltera, con niveles altos de instrucción, con familias numerosas de bajos niveles de dependencia económica. Por otro lado, la capacitación de la mano de obra en las maquiladoras es relativamente escasa.

Según la encuesta cOSIMCED, las diferencias encontradas en esas variables entre hombres y mujeres y entre maquiladoras fronterizas y no fronterizas son en muchos casos notables, de manera que sí justifican el análisis de esos grupos por separado.

En la siguiente sección, donde se presentan los impactos de las maquiladoras en los ingresos y el bienestar familiar de los trabajadores vistos por ellos mismos, se hace el análisis por separado, pero se considera, además, la condición de residencia (migrante o no migrante) como variable de control.

\section{EL IMPACTO DE LAS MAQUILADORAS EN EL BIENESTAR Y EL DESARROLLO DE LA COMUNIDAD}

\section{El impacto en el bienestar familiar}

El impacto de las maquiladoras en el bienestar de las familias de los trabajadores se detectó al través de indicadores tales como la importancia del ingreso proveniente de la maquila en los ingresos familiares totales y el impacto que el empleo en la maquila ha tenido en ciertas variables que reflejan bienestar.

Cuando se les preguntó si el ingreso proveniente de su empleo en la maquiladora era el único sostén económico de la familia, cerca del $85 \%$ del total de la muestra respondieron que no. Las diferencias de las respuestas entre trabajadores de acuerdo a su condición migratoria y a la localidad donde se encontraba su empleo se muestran en los cuadros 10 y 11 respectivamente. En el cuadro 10 se muestra una mayor dependencia 
CUADRO 10. Trabajadores en las maquiladoras según condición de residencia y si es o no el único ingreso familiar.

\begin{tabular}{lrrrrrr}
\hline Respuesta & \multicolumn{2}{c}{ Migrantes } & \multicolumn{2}{c}{ No migrantes } & \multicolumn{2}{c}{ Total } \\
& Abs. & $\%$ & Abs. & $\%$ & Abs. & $\%$ \\
\hline & & & & & & \\
Sf & 114 & 19.0 & 75 & 12.5 & 189 & 15.8 \\
No & 485 & 80.8 & 525 & 87.5 & 1010 & 84.2 \\
No respondio & 1 & 0.2 & & & 1 & 0.1 \\
Total & 600 & 100.0 & 600 & 100.0 & 1200 & 100.0 \\
& & & & & &
\end{tabular}

FUENTE: Encuesta COSIMCED.

familiar del ingreso por trabajo en la maquiladora en el grupo de migrantes que en el de no migrantes. En el cuadro 11, la dependencia mayor en esos términos se muestra entre los trabajadores maquiladores de Ciudad Juárez.

Por otro lado, la importancia familiar del ingreso fue mayor entre los trabajadores hombres que entre las mujeres, independientemente de la condición migratoria. De hecho, en el cuadro 12 se muestra que más del $90 \%$ de las mujeres entrevistadas afirmaron que su ingreso proveriente de las maquiladoras no era el único sostén económico de sus familias, mientras que la cifra correspondiente a los hombres fue de $73.9 \%$.

Considerando al mismo tiempo sexo y lugar de residencia, por un lado, y condición migratoria y lugar de residencia, por otro, se observa, en todas las ciudades estudiadas, la importancia mayor del ingreso por empleo en maquila entre las mujeres y entre los migrantes (cuadros 13 y 14).

CUADRO 11. Trabajadores en las maquiladoras.

Pregunta: ¿Lo que gana aquí es el único ingreso o sostén de su familia?

\begin{tabular}{|c|c|c|c|c|c|c|c|c|c|c|}
\hline \multirow[b]{2}{*}{ Respuesta } & \multicolumn{2}{|c|}{ Cd. Juḱrez } & \multicolumn{2}{|c|}{ Nvo. Laredo } & \multicolumn{2}{|c|}{ Tijuana } & \multicolumn{2}{|c|}{ Guadalajara } & \multicolumn{2}{|c|}{ Total } \\
\hline & Abs & $\%$ & Abs & $\%$ & Abs & $\%$ & Abs & $\%$ & Abs & $\%$ \\
\hline Sí & 58 & 19.3 & 32 & 10.7 & 46 & 15.3 & 53 & 17.7 & 189 & 15.8 \\
\hline No & 242 & 80.7 & 267 & 89.0 & 254 & 84.7 & 247 & 82.31 & 1010 & 84.2 \\
\hline No respondió & & & 1 & 0.3 & & & & & 1 & 0.1 \\
\hline Total & 300 & 100.0 & 300 & 100.0 & 300 & 100.0 & 300 & 100.01 & 12001 & 100.0 \\
\hline
\end{tabular}

FUENTE: Encuesta COSIMCED 
CUADRO 12. Trabajadores en las maquiladoras según condición de residencia, sexo y si es o no el único ingreso familiar.

\begin{tabular}{|c|c|c|c|c|c|c|c|c|c|c|c|c|}
\hline \multirow{3}{*}{ Respuesta } & \multicolumn{4}{|c|}{ Migrantes } & \multicolumn{4}{|c|}{ No migrantes } & \multicolumn{4}{|c|}{ Total } \\
\hline & \multicolumn{2}{|c|}{ Masculino } & \multicolumn{2}{|c|}{ Femenino } & \multicolumn{2}{|c|}{ Masculino } & \multicolumn{2}{|c|}{ Femenino } & \multicolumn{2}{|c|}{ Masculino } & \multicolumn{2}{|c|}{ Femenino } \\
\hline & Abs. & $\%$ & Abs & $\%$ & Abs. & $\%$ & Abs. & $\%$ & Abs. & $\%$ & Abs. & $\%$ \\
\hline Sí & 70 & 31.1 & 44 & 11.7 & 46 & 20.7 & 29 & 7.6 & 116 & 26.1 & 73 & 9.7 \\
\hline No & 155 & 68.9 & 330 & 88.0 & 174 & 79.1 & 351 & 92.4 & 329 & 73.9 & 681 & 90.2 \\
\hline No respondi反 & & & 1 & 0.3 & & & & & & & 1 & 0.1 \\
\hline Total & 225 & 100.0 & 375 & 100.0 & 230 & 100.0 & 380 & 100.0 & 445 & 100.0 & 755 & 100.0 \\
\hline
\end{tabular}

FUENTE: Encuenta COSIMCED. 
CUADRO 13. Trabajadores en las maquiladoras según ciudad, sexo y si es o no el único ingreso familiar

\begin{tabular}{|c|c|c|c|c|c|c|c|c|}
\hline \multirow[t]{2}{*}{ Ciudad/Respuesta } & \multicolumn{2}{|r|}{ Sí } & \multicolumn{2}{|c|}{ No } & \multirow{2}{*}{\multicolumn{2}{|c|}{$\begin{array}{l}\text { No respondió } \\
\text { Abs. } \%\end{array}$}} & \multicolumn{2}{|c|}{ Total } \\
\hline & Abs. & $\%$ & Abs. & $\%$ & & & Abs. & $\%$ \\
\hline \multicolumn{9}{|l|}{ Ciudad Juárez } \\
\hline masculino & 29 & 23.8 & 93 & 76.7 & & & 122 & 100.0 \\
\hline femenino & 29 & 16.3 & 149 & 83.7 & & & 178 & 100.0 \\
\hline \multicolumn{9}{|l|}{ Nuevo Laredo } \\
\hline masculino & 19 & 18.3 & 5 & 1.7 & & & 104 & 100.0 \\
\hline femenino & 13 & 6.6 & 182 & 92.9 & 1 & 0.5 & 196 & 100.0 \\
\hline \multicolumn{9}{|l|}{ Tijuana } \\
\hline masculino & 28 & 25.2 & 83 & 74.8 & & & 111 & 100.0 \\
\hline femenino & 18 & 9.5 & 171 & 90.5 & & & 189 & 100.0 \\
\hline \multicolumn{9}{|l|}{ Guadalajara } \\
\hline masculino & 40 & 37.0 & 68 & 63.0 & & & 108 & 100.0 \\
\hline femenino & 13 & 6.8 & 179 & 93.2 & & & 192 & 100.0 \\
\hline \multicolumn{9}{|l|}{ Total de Ciudades } \\
\hline masculino & 116 & 26.1 & 329 & 73.9 & & & 445 & 100.0 \\
\hline femenino & 73 & 9.7 & 681 & 90.2 & 2. 1 & 0.1 & 755 & 100.0 \\
\hline
\end{tabular}

FUENTE: Encuesta COSIMCED

Todo esto sugiere que, en buena medida, el empleo en maquiladoras es importante como fuente de ingresos a nivel individual y no tanto a nivel familiar, pero es un buen indicador del nivel de bienestar de la familia. Sin embargo, para obtener un indicador más efectivo del impacto de las maquiladoras en el bienestar de sus familias, se les preguntó a los entrevistados si su situación, en relación con algunas variables de bienestar - tales como alimentacion, vestido, servicios de salud, vivienda, educación, diversiones, ahorro, transporte y paseos- había mejorado, seguido igual o empeorado a consecuencia de su empleo en las maquiladoras.

A las respuestas en el sentido de que la situación había mejorado se les asignó un valor de 3 puntos; a las que indican que la situación había permanecido igual se les asignaron 2 puntos y se asignó un punto cuando la situación había empeorado. Los resultados de las respuestas, en términos de puntaje, se muestran en los cuadros 15 al 20. Para todas las variables 
CUADRO 14. Trabajadores en las maquiladoras según ciudad, condición de residencia y si es o no el único ingreso familiar.

\begin{tabular}{|c|c|c|c|c|c|c|c|c|}
\hline \multirow[t]{2}{*}{ Ciudad/Respuesta } & \multicolumn{2}{|c|}{ Sí } & \multicolumn{2}{|c|}{ No } & \multicolumn{2}{|c|}{ No respondió } & \multicolumn{2}{|c|}{ Total } \\
\hline & Abs. & $\%$ & Abs. & $\%$ & Abs & $\%$ & Abs. & $\%$ \\
\hline \multicolumn{9}{|l|}{ Ciudad Juárez } \\
\hline migrantes & 32 & 21.3 & 118 & 78.7 & & & 150 & 100.0 \\
\hline no migrantes & 26 & 17.3 & 124 & 82.7 & & & 150 & 100.0 \\
\hline \multicolumn{9}{|l|}{ Nuevo Laredo } \\
\hline migrantes & 23 & 15.3 & 126 & 84.0 & 1 & 0.7 & 150 & 100.0 \\
\hline no migranies & 9 & 6.0 & 141 & 94.0 & & & 150 & 100.0 \\
\hline \multicolumn{9}{|l|}{ Tijuana } \\
\hline migrantes & 27 & 18.0 & 123 & 82.0 & & & 150 & 100.0 \\
\hline no migrantes & 19 & 12.7 & 131 & 87.3 & & & 150 & 100.0 \\
\hline \multicolumn{9}{|l|}{ Guadalajara } \\
\hline migrantes & 32 & 21.3 & 118 & 78.7 & & & 150 & 100.0 \\
\hline no migrantes & 21 & 14.0 & 129 & 86.0 & & & 150 & 100.0 \\
\hline \multicolumn{9}{|l|}{ Total de Ciudades } \\
\hline migrantes & 114 & 19.0 & 485 & 80.8 & 1 & 0.2 & 600 & 99.8 \\
\hline no migrantes & 75 & 12.5 & 525 & 87.5 & & & 600 & 100.0 \\
\hline
\end{tabular}

FUENTE: Encuesta COSIMCED.

incluidas se encontraron promedios mayores al valor 2 , lo que indica que, en promedio, los trabajadores dijeron que su situación había más bien mejorado que quedado igual.

Por otro lado, y no obstante la considerable cercanía de los valores promedio que se observaron -independientemente de los cruces que se hagan por las variables de control-, es importante destacar las diferencias encontradas. Por ejemplo, los puntajes más altos se encontraron en alimentación y vestido, mientras que los más bajos se encontraron en vivienda, transporte, y servicios de salud, lo que deja en un nivel intermedio a educación, diversiones, ahorro y paseos.

Lo anterior muestra que, no obstante que el ingreso proveniente de las maquiladoras no es en muchos casos el único sostén económico familiar, sí ha permitido mejorías en los niveles de aseguramiento de satisfactores básicos como la alimentación y el vestido. Por otro lado, los resultados también indican que la mejoría en los ingresos familiares por el empleo en las maquiladoras no ha sido lo suficientemente fuerte como para mejorar la vivienda de los trabajadores ni sus medios de transporte. 
CUADRO 15. Trabajadores en las maquiladoras según sexo y cambios en las condiciones de vida a partir del ingreso a las maquiladoras. Promedios

\begin{tabular}{llll}
\hline Concepto & Hombres & Mujeres & Total \\
\hline Alimentación & 2.6 & 2.6 & 2.6 \\
Vestido & 2.6 & 2.3 & 2.4 \\
Salud & 2.3 & 2.2 & 2.2 \\
Vivienda & 2.1 & 2.4 & 2.3 \\
Educación & 2.4 & 2.4 & 2.4 \\
Diversiones & 2.4 & 2.5 & 2.4 \\
Ahorro & 2.4 & 2.2 & 2.3 \\
Transporte & 2.3 & 2.3 & 2.3 \\
Paseos & 2.4 & 2.4 & 2.4 \\
Total & 2.4 & 2.4 & 2.4 \\
\hline
\end{tabular}

FUENTE: Encuesta COSIMCED.

CUADRO 16. Trabajadores en las maquiladoras según condición de residencia y cambios en las condiciones de vida a partir del ingreso a las maquiladoras. Promedios.

\begin{tabular}{lccc}
\hline Concepto & Migrantes & No migrantes & Total \\
\hline Alimentación & 2.6 & 2.5 & 2.6 \\
Vestido & 2.6 & 2.6 & 2.6 \\
Salud & 2.3 & 2.3 & 2.3 \\
Vivienda & 2.2 & 2.1 & 2.1 \\
Educación & 2.4 & 2.4 & 2.4 \\
Diversiones & 2.4 & 2.4 & 2.4 \\
Ahorro & 2.4 & 2.5 & 2.4 \\
Transporte & 2.2 & 2.2 & 2.2 \\
Paseos & 2.3 & 2.4 & 2.3 \\
Total & 2.4 & 2.4 & 2.4 \\
& & & \\
\hline
\end{tabular}

FUENTE: Encuesta COSIMCED. 
CUADRO 17. Trabajadores en las maquiladoras según sexo, condición de residencia y cambios en las condiciones de vida a partir del ingreso a las maquiladoras. Promedios.

Concepto

Hombres

Mujeres

Total

Migr. No migr. Migr. No migr. Migr. No migr.

$\begin{array}{lllllll}\text { Alimentación } & 2.6 & 2.6 & 2.5 & 2.5 & 2.6 & 2.5 \\ \text { Vestido } & 2.6 & 2.5 & 2.5 & 2.6 & 2.6 & 2.6 \\ \text { Salud } & 2.4 & 2.2 & 2.3 & 2.3 & 2.3 & 2.3 \\ \text { Vivienda } & 2.2 & 2.1 & 2.2 & 2.1 & 2.2 & 2.1 \\ \text { Educación } & 2.4 & 2.4 & 2.4 & 2.4 & 2.4 & 2.4 \\ \text { Diversiones } & 2.4 & 2.4 & 2.4 & 2.4 & 2.4 & 2.4 \\ \text { Ahorro } & 2.4 & 2.4 & 2.4 & 2.5 & 2.4 & 2.5 \\ \text { Transporte } & 2.2 & 2.3 & 2.1 & 2.2 & 2.2 & 2.2 \\ \text { Paseos } & 2.4 & 2.4 & 2.3 & 2.4 & 2.3 & 2.4 \\ \text { Total } & 2.4 & 2.4 & 2.4 & 2.4 & 2.4 & 2.4 \\ & & & & & & \end{array}$

FUENTE: Encuesta COSIMCED.

CUADRO 18. Trabajadores en las maquiladoras según condición de residencia, sexo y cambios en las condiciones de vida a partir del ingreso a las maquiladoras. Promedios.

\begin{tabular}{|c|c|c|c|c|c|c|}
\hline \multirow[t]{2}{*}{ Concepto } & \multicolumn{2}{|c|}{ Migrantes } & \multicolumn{2}{|c|}{ No migrantes } & \multicolumn{2}{|c|}{ Total } \\
\hline & Mas. & Fem. & Mas. & Fem. & Mas. & Fem. \\
\hline Alimentación & 2.6 & 2.5 & 2.6 & 2.5 & 2.6 & 2.6 \\
\hline Vestido & 2.6 & 2.5 & 2.5 & 2.6 & 2.6 & 2.3 \\
\hline Salud & 2.4 & 2.3 & 2.2 & 2.3 & 2.3 & 2.2 \\
\hline Vivienda & 2.2 & 2.2 & 2.1 & 2.1 & 2.1 & 2.4 \\
\hline Educación & 2.4 & 2.4 & 2.4 & 2.4 & 2.4 & 2.4 \\
\hline Diversiones & 2.4 & 2.4 & 2.4 & 2.4 & 2.4 & 2.5 \\
\hline Ahorro & 2.4 & 2.4 & 2.4 & 2.5 & 2.4 & 2.2 \\
\hline Transporte & 2.2 & 2.1 & 2.3 & 2.2 & 2.3 & 2.3 \\
\hline Paseos & 2.4 & 2.3 & 2.4 & 2.4 & 2.4 & 2.4 \\
\hline Total & 2.4 & 2.4 & 2.4 & 2.4 & 2.4 & 2.4 \\
\hline
\end{tabular}

FUENTE: Encuesta COSIMCED. 
CUADRO 19. Trabajadores en las maquiladoras según ciudad, sexo y cambios en las condiciones de vida a partir del ingreso a las maquiladoras. Promedios.

Concepto Cd. Juárez Nvo. Laredo Tijuana Guadalajara Total Mas. Fem. Mas. Fem. Mas. Fem. Mas. Fem Mas.Fem.

\begin{tabular}{lllllllllll}
\hline Alimentación & 2.7 & 2.6 & 2.6 & 2.6 & 2.5 & 2.5 & 2.5 & 2.5 & 2.6 & 2.6 \\
Vestido & 2.6 & 2.6 & 2.7 & 2.6 & 2.6 & 2.3 & 2.5 & 2.3 & 2.6 & 2.3 \\
Salud & 2.4 & 2.3 & 2.3 & 2.3 & 2.3 & 2.1 & 2.2 & 2.1 & 2.3 & 2.2 \\
Vivienda & 2.2 & 2.1 & 2.2 & 2.2 & 2.1 & 2.4 & 2.0 & 2.4 & 2.1 & 2.4 \\
Educación & 2.4 & 2.3 & 2.5 & 2.4 & 2.3 & 2.4 & 2.4 & 2.5 & 2.4 & 2.4 \\
Diversiones & 2.5 & 2.4 & 2.3 & 2.5 & 2.5 & 2.5 & 2.4 & 2.5 & 2.4 & 2.5 \\
Ahorro & 2.5 & 2.5 & 2.5 & 2.5 & 2.3 & 2.1 & 2.3 & 2.2 & 2.4 & 2.2 \\
Transporte & 2.3 & 2.1 & 2.2 & 2.2 & 2.3 & 2.3 & 2.2 & 2.4 & 2.3 & 2.3 \\
Paseos & 2.4 & 2.3 & 2.3 & 2.3 & 2.4 & 2.3 & 2.4 & 2.4 & 2.4 & 2.4 \\
Total & 2.5 & 2.4 & 2.4 & 2.4 & 2.4 & 2.3 & 2.3 & 2.4 & 2.4 & 2.4
\end{tabular}

FUENTE: Encuesta COSIMCED.

CUADRO 20. Trabajadores en las maquiladoras según ciudad, condición de residencia y cambios en las condiciones de vida a partir del ingreso a las maquiladoras. Promedios.

Concepto Cd. Juárez Nvo. Laredo Tijuana Guadalajara Total mig. no mig. mig. no mig. mig. no mig. mig. no mig. mig. no mig.

\begin{tabular}{lllllllllll}
\hline Alimentación & 2.7 & 2.6 & 2.7 & 2.6 & 2.4 & 2.5 & 2.5 & 2.5 & 2.6 & 2.5 \\
Vestido & 2.6 & 2.6 & 2.7 & 2.6 & 2.5 & 2.5 & 2.5 & 2.5 & 2.6 & 2.6 \\
Salud & 2.3 & 2.3 & 2.3 & 2.3 & 2.3 & 2.3 & 2.3 & 2.3 & 2.3 & 2.3 \\
Vivienda & 2.2 & 2.2 & 2.3 & 2.2 & 2.1 & 2.1 & 2.1 & 2.1 & 2.2 & 2.1 \\
Educación & 2.3 & 2.4 & 2.4 & 2.5 & 2.3 & 2.4 & 2.4 & 2.4 & 2.4 & 2.4 \\
Diversión & 2.5 & 2.4 & 2.4 & 2.5 & 2.4 & 2.4 & 2.4 & 2.4 & 2.4 & 2.4 \\
Ahorro & 2.4 & 2.5 & 2.5 & 2.4 & 2.4 & 2.5 & 2.3 & 2.5 & 2.4 & 2.5 \\
Transporte & 2.2 & 2.2 & 2.2 & 2.2 & 2.1 & 2.3 & 2.1 & 2.3 & 2.2 & 2.2 \\
Paseos & 2.4 & 2.4 & 2.3 & 2.4 & 2.3 & 2.4 & 2.4 & 2.4 & 2.3 & 2.4 \\
Total & 2.4 & 2.4 & 2.4 & 2.4 & 2.3 & 2.4 & 2.3 & 2.4 & 2.4 & 2.4
\end{tabular}

FUENTE: Encuesta COSIMCED. 
Por último, la opinión de los entrevistados en cuanto al impacto del ingreso por maquiladoras en variables tales como los paseos y las diversiones, que son importantes en general pero aún más entre las mujeres, es consistente con lo que ya se ha visto: que dicho ingreso no es el único sostén de la familia, pero les permite ampliar sus horizontes de bienestar vía variables asociadas normalmente con niveles adecuados de ingreso.

\section{El impacto en el desarrollo de la comunidad}

En cuanto al impacto de las maquiladoras en los diferentes aspectos de la vida de las comunidades donde se encuentran operando, las apreciaciones de los líderes de opinión locales fueron captadas al través de la aplicación de un cuestionario especial a líderes obreros, académicos, funcionarios gubernamentales, representantes de industrias y representantes de comerciantes, entre otros, de las cuatro ciudades, según se muestra en el cuadro 21. La intención de dicho cuestionario fue detectar el grado de conocimiento que tenían de las maquiladoras y su funcionamiento quienes en cierto momento podrían influir en las modificaciones del programa maquilador. Asimismo se intentó detectar la dirección de las modificaciones que en dado caso ellos propondrían, al través del conocimiento de su opinión acerca del impacto social que han tenido las maquiladoras, de lo que ellos creen que podría pasar con las maquiladoras en el futuro, y de lo que ellos piensan que debería hacerse, a manera de modificaciones del programa para su aprovechamiento al máximo a favor de México.

En términos generales se encontró un conocimiento no muy amplio del programa de maquiladoras entre los líderes entrevistados. Por ejemplo, no obstante que existen maquiladoras en México desde hace más de 20 años, solamente el $42.5 \%$ de ellos manifestaron tener conocimiento de que las maquiladoras en su ciudad tenían más de 15 affos (cuadro 22). Por otro lado, cuando se les preguntó si habían existido maquiladoras en otras ciudades de México, antes de que las hubiera en la localidad de referencia, el $17.5 \%$ de ellos manifestó no conocer el dato (cuadro 23). Cuando se les preguntó acerca del número de maquiladoras que existian en su ciudad al momento de la entrevista las respuestas no mejoraron sustancialmente. Según los datos presentados en el cuadro 1, en enero de 1989 existían, aproximadamente 400 plantas maquiladoras en Tijuana, 250 en Ciudad Juárez, 30 en Nuevo Laredo y 35 en Guadalajara. Según la mayoría de los líderes entrevistados había más de 150 plantas en Ciudad Juárez, menos de 100 en Nuevo Laredo, más de 100 en Tijuana, y menos de 150 en Guadalajara (cuadro 24).

También se les preguntó el número de maquiladoras de su ciudad que ellos conocían. Las respuestas se incluyen en el cuadro 25 y muestran que la 
CUADRO 21. Líderes de opinión según cargo que tiene o desempeña.

\begin{tabular}{|c|c|c|c|c|c|c|c|c|c|c|c|c|c|c|}
\hline \multirow[b]{2}{*}{ Ciudad } & \multicolumn{2}{|c|}{ Académico } & \multicolumn{2}{|c|}{ Líder obrero } & \multicolumn{2}{|c|}{ Funcionario } & \multicolumn{2}{|c|}{ Industrial } & \multicolumn{2}{|c|}{ Comerciante } & \multicolumn{2}{|r|}{ Otro } & \multicolumn{2}{|c|}{ Total } \\
\hline & Abs. & $\%$ & Abs. & $\%$ & Abs. & $\%$ & Abs. & $\%$ & Abs. & $\%$ & Abs. & $\%$ & Abs. & $\%$ \\
\hline Cd. Juárez & 2 & 33.3 & 2 & 25.0 & 3 & 37.5 & 1 & 11.1 & 2 & 28.6 & & & 10 & 25.0 \\
\hline Nvo. Laredo & 1 & 16.7 & 3 & 37.5 & 1 & 12.5 & 2 & 22.2 & 2 & 28.6 & 1 & 50.0 & 10 & 25.0 \\
\hline Tijuana & 1 & 16.7 & 1 & 12.5 & 2 & 25.0 & 3 & 33.3 & 2 & 28.6 & 1 & 50.0 & 10 & 25.0 \\
\hline Guadalajara & 2 & 33.3 & 2 & 25.0 & 2 & 25.0 & 3 & 33.3 & 1 & 14.3 & & & 10 & 25.0 \\
\hline Total & 6 & 100.0 & 8 & 100.0 & 8 & 100.0 & 9 & 100.0 & 7 & 100.0 & 2 & 100.0 & 40 & 100.0 \\
\hline
\end{tabular}

FUENTE: Encuesta COSIMCED. 
CUADRO 22. Líderes de opinión: ¿Desde hace cuantos años existen maquiladoras en esta ciudad? (participación porcentual).

\begin{tabular}{|c|c|c|c|c|c|c|c|c|c|c|c|c|c|c|}
\hline Años & \multicolumn{2}{|c|}{$\begin{array}{c}1 \text { a } 5 \\
\text { Abs. \% }\end{array}$} & \multicolumn{2}{|c|}{$\begin{array}{r}6 \text { a } 10 \\
\text { Abs. } \%\end{array}$} & \multicolumn{2}{|c|}{$\begin{array}{l}11 \text { a } 15 \\
\text { Abs. \% }\end{array}$} & \multicolumn{2}{|c|}{$\begin{array}{l}16 \text { a } 20 \\
\text { Abs. } \%\end{array}$} & \multicolumn{2}{|c|}{$\begin{array}{l}21 \text { a } 25 \\
\text { Abs. } \%\end{array}$} & $\begin{array}{l}26 \text { a } 30 \\
\text { Abs. \% }\end{array}$ & \multirow{2}{*}{$\begin{array}{c}\begin{array}{c}\text { No respondió } \\
\text { Abs. \% }\end{array} \\
1100.0\end{array}$} & \multicolumn{2}{|c|}{$\begin{array}{c}\text { Total } \\
\text { Abs. \% }\end{array}$} \\
\hline d. Juárez & 1 & 25.0 & 6 & 46.2 & & & 2 & 16.7 & & & & & 10 & 25.0 \\
\hline Jvo. Laredo & & & & & 2 & 40.0 & 4 & 33.3 & 2 & 66.7 & 2100.0 & & 10 & 25.0 \\
\hline Tijuana & & & 2 & 15. & 2 & 40.0 & 5 & 41.7 & 1 & 33.3 & & & 10 & 25.0 \\
\hline Guadalajara & 3 & 75.0 & 5 & 38.5 & 1 & 20.0 & 1 & 8.3 & & & & & 10 & 25.0 \\
\hline Total & 4 & 100.0 & 13 & 100.0 & 5 & 100.0 & 12 & 100.0 & 3 & 100.0 & 2100.0 & $\begin{array}{ll}1 & 100.0\end{array}$ & 40 & 100.0 \\
\hline
\end{tabular}

FUENTE: Encuesta COSIMCED. 
CUADRO 23. Líderes de opinión. ¿Hubo maquiladoras en otras ciudades de México, antes de que hubiera en esta ciudad?

\begin{tabular}{|c|c|c|c|c|c|c|c|c|c|}
\hline \multirow[t]{2}{*}{ Ciudad } & \multicolumn{2}{|c|}{ Si existieron } & \multicolumn{2}{|c|}{ No exist. } & \multicolumn{2}{|c|}{ No sabe } & No respondió & \multicolumn{2}{|c|}{ Total } \\
\hline & Abs & $\%$ & Abs & $\%$ & Abs & $\%$ & Abs \% & Abs & $\%$ \\
\hline Cd. Juárez & 7 & 25.0 & & & 3 & 42.9 & & 10 & 25.0 \\
\hline Nvo. Laredo & 6 & 21.4 & 3 & 75.0 & 1 & 14.3 & & 10 & 25.0 \\
\hline Tijuana & 7 & 25.0 & 1 & 25.0 & 2 & 28.6 & & 10 & 25.0 \\
\hline Guadalajara & 8 & 28.6 & & & 1 & 14.3 & 1100.0 & 10 & 25.0 \\
\hline Total & 28 & 100.0 & & 100.0 & 7 & 100.0 & 1100.0 & 40 & 100.0 \\
\hline
\end{tabular}

FUENTE: Encuesta COSIMCED.

mayoría de los entrevistados, el $52.5 \%$, conocen entre una y cinco maquiladoras locales, mientras que solamente el $5 \%$ no conocen ninguna de ellas.

La apreciación del impacto social de las maquiladoras se obtuvo al través de su opinión sobre el impacto en algunas variables seleccionadas tales como el desarrollo económico de México y de la región donde se encuentran ubicadas; los servicios públicos, las condiciones de vida y la conciencia social de la ciudad; la unidad, el bienestar y la educación de las familias de los trabajadores; la salud, la superación y la libertad del trabajador maquilador.

A las respuestas se les asignó un valor de 4 puntos cuando el impacto específico era considerado como muy positivo; de 3 puntos cuando era solamente positivo; de 2 puntos cuando negativo y de 1 punto cuando era considerado muy negativo. El resumen de las respuestas se incluye en el cuadro 26, y muestran que, en opinión de los entrevistados, los impactos más positivos de las maquiladoras se dan en el desarrollo económico regional, en el bienestar familiar y en la superación del trabajador, mientras que los menos positivos se dan en los servicios públicos locales, la conciencia social de la ciudad y la unidad de las familias de los trabajadores. En general, sin embargo, se encontró una opinión global positiva acerca del impacto de las maquiladoras en las variables seleccionadas.

Por otro lado, también se les preguntó lo que ellos creían que pasaría en su comunidad si se terminara el programa mexicano de maquiladoras. Específicamente se les pregunt $\delta$ si el efecto de dicha terminación sería muy importante, poco importante o nulo en el aumento de desempleo, la baja de la actividad económica, las presiones sociales, la caída en los ingresos familiares, la desindustrialización general, la migración a Estados Unidos, 
CUADRO 24. Líderes de opinión ¿Cuántas maquiladoras existen actualmente aquí?

\begin{tabular}{|c|c|c|c|c|c|c|c|c|c|c|c|c|c|c|c|}
\hline Ciudad & \multicolumn{2}{|c|}{$\begin{array}{r}1 \text { a } 50 \\
\text { Abs. } \%\end{array}$} & \multicolumn{2}{|c|}{$\begin{array}{l}51 \text { a } 100 \\
\text { Abs. } \%\end{array}$} & \multicolumn{2}{|c|}{$\begin{array}{l}101 \text { a } 150 \\
\text { Abs. } \%\end{array}$} & \multicolumn{2}{|c|}{$\begin{array}{l}151 \text { a } 200 \\
\text { Abs. } \%\end{array}$} & \multicolumn{2}{|c|}{$\begin{array}{l}201 \text { a } 250 \\
\text { Abs. } \%\end{array}$} & \multicolumn{2}{|c|}{$\begin{array}{l}251 \text { a } 300 \\
\text { Abs. } \%\end{array}$} & $\begin{array}{l}\text { Más de } 300 \\
\text { Abs. \% }\end{array}$ & \multicolumn{2}{|c|}{$\begin{array}{c}\text { Total } \\
\text { Abs. \% }\end{array}$} \\
\hline Cd. Juárez & & & & & 1 & & 5 & 71.4 & 4 & 80.0 & & & & 10 & 25.0 \\
\hline Nvo. Laredo & 4 & 40.0 & 6 & 66.7 & & & & & & & & & & 10 & 25.0 \\
\hline Tijuana & & & 1 & 11.1 & 3 & 50.0 & 2 & 28.6 & 1 & 20.0 & 1 & 100.0 & 2100.0 & 10 & 25.0 \\
\hline Guadalajara & 6 & 60.0 & 2 & 22.2 & 2 & 33.3 & & & & & & & & 10 & 25.0 \\
\hline Total & 10 & 100.0 & 9 & 100.0 & 6 & 100.0 & 7 & 100.0 & 5 & 100.0 & 1 & 100.0 & 2100.0 & 40 & 100.0 \\
\hline
\end{tabular}

FUENTE: Encuesta cosIMCED. 
CUADRO 25. Líderes de opinión. ¿Según el número de maquiladoras que conocen en la ciudad de la encuesta?

\begin{tabular}{|c|c|c|c|c|c|c|c|c|c|c|c|c|c|c|}
\hline \multirow[t]{2}{*}{ Ciudad } & \multicolumn{2}{|c|}{ Ninguna } & \multicolumn{2}{|c|}{1 a 5} & \multicolumn{2}{|c|}{6 a 10} & \multicolumn{2}{|c|}{11 a 15} & \multicolumn{2}{|c|}{16 a 20} & \multicolumn{2}{|c|}{ más de 20} & \multicolumn{2}{|c|}{ Total } \\
\hline & Abs. & $\%$ & Abs & $\%$ & Abs. & $\%$ & Abs & $\%$ & Abs & $\%$ & Abs & $\%$ & Abs & $\%$ \\
\hline Cd. Juárez & & & 6 & 28.6 & 2 & 66.7 & & & 1 & 20.0 & 1 & 25.0 & 10 & 25.0 \\
\hline Nvo. Laredo & 1 & 50.0 & 6 & 28.6 & & & 1 & 20.0 & 1 & 20.0 & 1 & 25.0 & 10 & 25.0 \\
\hline Tijuana & & & 4 & 19.0 & & & 2 & 40.0 & 2 & 40.0 & 2 & 50.0 & 10 & 25.0 \\
\hline Guadalajara & 1 & 50.0 & -5 & 23.8 & 1 & 33.3 & 2 & 40.0 & 1 & 20.0 & & & 10 & 25.0 \\
\hline Total & 2 & 100.0 & 21 & 100.0 & 3 & 100.0 & 5 & 100.0 & 5 & 100.0 & 4 & 100.0 & 40 & 100.0 \\
\hline
\end{tabular}

FUENTE: Encuesta COSIMCED. 
CUADRO 26. Líderes de opinión. Según el impacto de las maquiladoras en algunas variables socioeconómicas. Promedios.

\begin{tabular}{lccccc}
\hline Concepto & $\begin{array}{c}\text { Ciudad } \\
\text { Juárez }\end{array}$ & $\begin{array}{c}\text { Nuevo } \\
\text { Laredo }\end{array}$ & Tijuana & $\begin{array}{c}\text { Guada- } \\
\text { lajara }\end{array}$ & Total \\
\hline En el desarrollo econ. de Méx. & 3.1 & 3.5 & 3.8 & 3.6 & 3.5 \\
En el desarrollo econ. regional & 3.8 & 3.7 & 3.9 & 3.5 & 3.7 \\
En los serv. públicos locales & 2.5 & 2.7 & 2.6 & 3.3 & 2.8 \\
En las condiciones de vida locales & 3.1 & 3.4 & 3.3 & 3.3 & 3.3 \\
En la conciencia social de la cd. & 2.4 & 3.1 & 3.2 & 3.3 & 3.0 \\
En la unidad familiar de los tra- & & & & & \\
bajadores de las maquiladoras & 2.4 & 3.5 & 3.3 & 3.6 & 3.2 \\
En el bienestar familiar de los & & & & & \\
trabajadores de las maquiladoras & 3.2 & 3.7 & 3.9 & 3.7 & 3.6 \\
$\begin{array}{l}\text { En la educ. de la familia de los } \\
\text { trabajadores de las maquiladoras }\end{array}$ & 3.0 & 3.4 & 3.8 & 3.3 & 3.4 \\
En la salud del trabajador & 3.1 & 2.9 & 3.9 & 3.5 & 3.4 \\
$\begin{array}{l}\text { En la superación del trabajador } \\
\text { En la libertad del trabajador }\end{array}$ & 3.6 & 3.0 & 3.9 & 3.8 & 3.6 \\
Total & 2.4 & 3.4 & 3.5 & 3.4 & 3.2 \\
\end{tabular}

FUENTE: Encuesta COSIMCED.

NOTA: La pregunta hecha a los líderes de opinión incluía la siguiente observación, favor de indicar si en su opinión. Ese impacto ha sido muy positivo (4), simplemente positivo (3), negativo (2) o muy negativo (1).

la migración al resto de México y el aumento en la vagancia y la delincuencia. En el cuadro 27 se han incluido los valores promedio de las respuestas, considerando los siguientes valores: 4, si muy importante; 3 , si solo importante; 2 , si poco importante, y; 1 , si el efecto es considerado nulo. Las respuestas indican claramente que los líderes de opinión entrevistados identifican a las maquiladoras más como una fuente de ingresos familiares y empleo que como un factor-de industrialización, independientemente del lugar de que se trate. Por otro lado, los valores promedio del cuadro 27 son consistentes con las apreciaciones de los líderes ya mencionadas, en cuanto al impacto de las maquiladoras en la vida de la comunidad.

Sin duda esas apreciaciones fueron las responsables de que los entrevistados, en su mayoría, recomendaran que se fomentaran las maquiladoras. De hecho, según los datos del cuadro 28 , con excepción de los entrevistados 
CUADRO 27. Líderes de opinión. Según la importancia de posibles efectos en el supuesto de que se terminara el programa de las maquiladoras en México (promedios).

\begin{tabular}{|c|c|c|c|c|c|}
\hline Efectos & $\begin{array}{l}\text { Ciudad } \\
\text { Juárez }\end{array}$ & $\begin{array}{l}\text { Nuevo } \\
\text { Laredo }\end{array}$ & Tijuana & $\begin{array}{l}\text { Guada- } \\
\text { lajara }\end{array}$ & Total \\
\hline Aumento del desempleo & 3.8 & 3.7 & 4.0 & 3.0 & 3.6 \\
\hline Baja en la actividad económica & 3.8 & 3.4 & 3.6 & 2.8 & 3.4 \\
\hline Presiones sociales & 3.9 & 3.3 & 3.9 & 3.2 & 3.6 \\
\hline Caída en los ingresos familiares & 3.9 & 3.8 & 4.0 & 3.5 & 3.8 \\
\hline Desindustrialización general & 2.0 & 2.1 & 3.1 & 2.1 & 2.3 \\
\hline Migración a Estados Unidos & 3.9 & 3.4 & 3.5 & 2.6 & 3.4 \\
\hline Migración al resto de México & 3.0 & 3.1 & 3.0 & 2.6 & 2.9 \\
\hline Vagancia y delincuencia & 3.7 & 3.2 & 4.0 & 3.2 & 3.5 \\
\hline Total & 3.5 & 3.3 & 3.6 & 2.9 & 3.3 \\
\hline
\end{tabular}

FUENTE: Encuesta COSIMCED.

NOTA: La pregunta hecha a los líderes de opinión incluía la siguiente observación: favor de indicar si el efecto sería muy importante (4), solamente importante (3), poco importante (2) o nulo (1).

en Guadalajara, los de las demás ciudades opinaron mayoritariamente que se deberían fomentar las maquiladoras o cuando mucho controlarlas. Solamente un entrevistado, académico de Nuevo Laredo, opinó que se deberían eliminar. Por otro lado, cuando se les preguntó su opinión acerca de las acciones que se deberían hacer para aprovechar al máximo las

CUADRO 28. Líderes de opinión. ¿Qué considera usted que debe hacerse con las maquiladoras? (participación porcentual).

\begin{tabular}{|c|c|c|c|c|c|c|c|c|}
\hline \multirow[t]{2}{*}{ Ciudad } & \multicolumn{2}{|c|}{ Fomentarlas } & \multicolumn{2}{|c|}{ Controlarlas } & \multicolumn{2}{|c|}{ Eliminarlas } & \multicolumn{2}{|c|}{ Total } \\
\hline & Abs. & $\%$ & Abs. & $\%$ & Abs. & $\%$ & Abs. & $\%$ \\
\hline Ciudad Juárez & 6 & 27.3 & 4 & 23.5 & & & 10 & 25.0 \\
\hline Nuevo Laredo & 5 & 22.7 & 4 & 23.5 & & 100.0 & 10 & 25.0 \\
\hline Tijuana & 7 & 31.8 & 3 & 17.6 & & & 10 & 25.0 \\
\hline Guadalajara & 4 & 18.2 & 6 & 35.3 & & & 10 & 25.0 \\
\hline Total & 22 & 100.0 & 17 & 100.0 & 1 & 100.0 & 40 & 100.0 \\
\hline
\end{tabular}

FUENTE: Encuesta COSIMCED, 
CUADRO 29. Líderes de opinión. ¿Qué cree usted que debe hacerse para que la maquila se aproveche al máximo a favor de México? (absolutos).

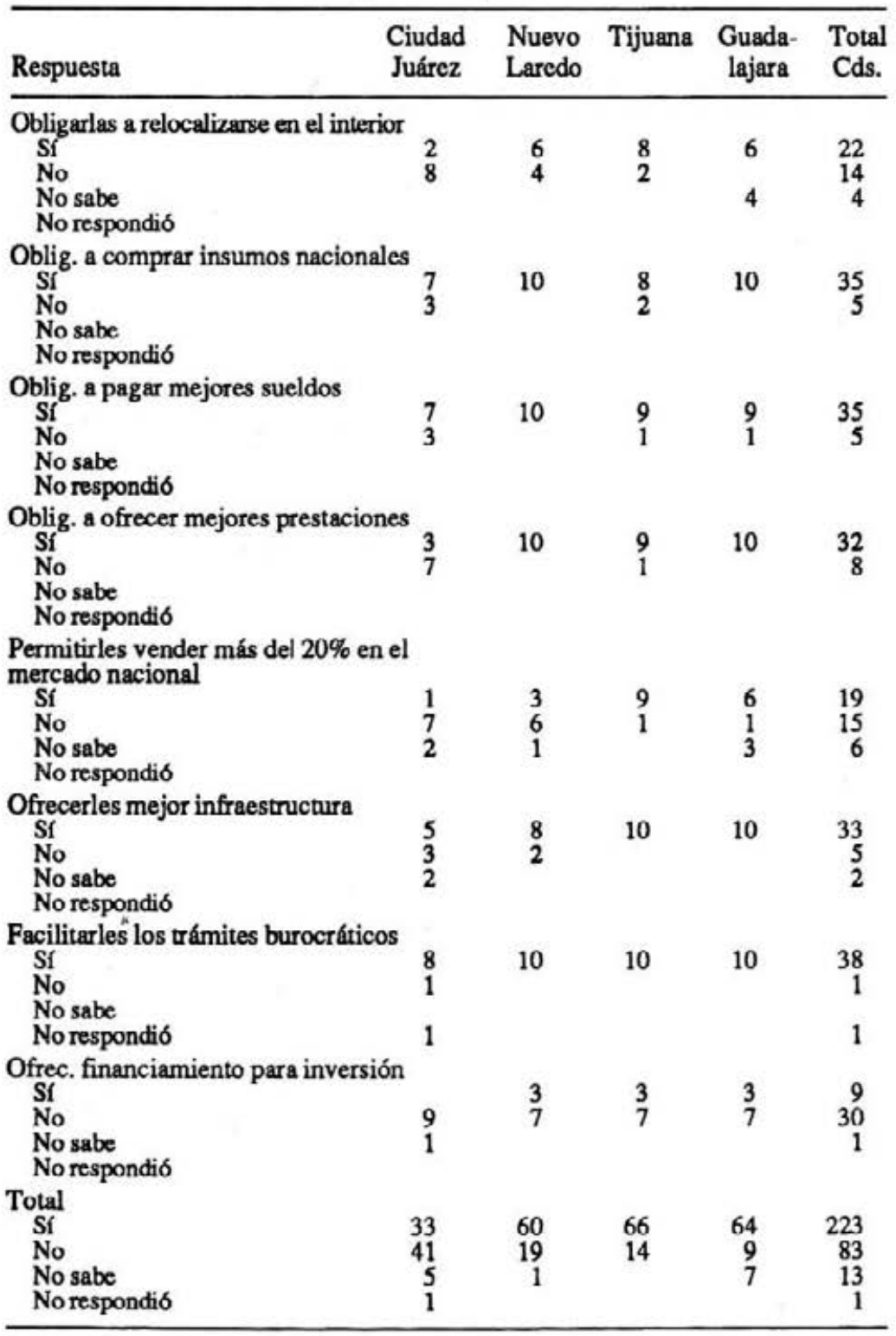

FUENTE: Encuesta COSIMCED. 
CUADRO 30. Líderes de opinión. ¿Qué cree usted que debe hacerse para que la maquila se aproveche al máximo a favor de México? (porcentajes).

\begin{tabular}{|c|c|c|c|c|c|}
\hline Respuesta & $\begin{array}{l}\text { Ciudad } \\
\text { Juárez }\end{array}$ & $\begin{array}{l}\text { Nuevo } \\
\text { Laredo }\end{array}$ & Tijuana & $\begin{array}{l}\text { Guada- } \\
\text { lajara }\end{array}$ & $\begin{array}{l}\text { Total } \\
\text { Cdes. }\end{array}$ \\
\hline \multicolumn{4}{|l|}{ Oblig. a relocalizarse en el interior } & 60.0 & \\
\hline $\begin{array}{l}\text { No } \\
\text { No sabe } \\
\text { No respondió }\end{array}$ & 80.0 & 40.0 & 20.0 & 40.0 & $\begin{array}{l}35.0 \\
10.0\end{array}$ \\
\hline $\begin{array}{l}\text { Oblig. a comprar insumos nales. } \\
\text { Sî } \\
\text { No } \\
\text { No sabe } \\
\text { No respondio }\end{array}$ & $\begin{array}{l}70.0 \\
30.0\end{array}$ & 100.0 & $\begin{array}{l}80.0 \\
70.0\end{array}$ & 100.0 & $\begin{array}{l}87.5 \\
12.5\end{array}$ \\
\hline $\begin{array}{l}\text { Oblig. a pagar mejores sueldos } \\
\text { Si } \\
\text { No } \\
\text { No sabe } \\
\text { No respondio }\end{array}$ & $\begin{array}{l}70.0 \\
30.0\end{array}$ & 100.0 & $\begin{array}{l}90.0 \\
10.0\end{array}$ & $\begin{array}{l}90.0 \\
10.0\end{array}$ & $\begin{array}{l}87.5 \\
12.5\end{array}$ \\
\hline $\begin{array}{l}\text { Oblig. a ofrecer mejores prest. } \\
\text { S1 } \\
\text { No } \\
\text { No sabe } \\
\text { No respondio }\end{array}$ & $\begin{array}{l}30.0 \\
70.0\end{array}$ & 100.0 & $\begin{array}{l}90.0 \\
10.0\end{array}$ & 100.0 & $\begin{array}{l}80.0 \\
20.0\end{array}$ \\
\hline $\begin{array}{l}\text { Permitirles vender más del } \\
20 \% \text { en el mercado nal. } \\
\text { Si } \\
\text { No } \\
\text { No sabe } \\
\text { No respondió }\end{array}$ & $\begin{array}{l}10.0 \\
70.0 \\
20.0\end{array}$ & $\begin{array}{l}30.0 \\
60.0 \\
10.0\end{array}$ & $\begin{array}{l}90.0 \\
10.0\end{array}$ & $\begin{array}{l}60.0 \\
10.0 \\
30.0\end{array}$ & $\begin{array}{l}47.5 \\
37.5 \\
15.0\end{array}$ \\
\hline $\begin{array}{l}\text { Ofrecerles mejor infraestructura } \\
\text { Sí } \\
\text { No } \\
\text { No sabe } \\
\text { No respondió }\end{array}$ & $\begin{array}{l}30.0 \\
20.0\end{array}$ & $\begin{array}{l}80.0 \\
20.0\end{array}$ & 100.0 & 100.0 & $\begin{array}{r}82.5 \\
12.5 \\
5.0\end{array}$ \\
\hline $\begin{array}{l}\text { Facilitarles los trámites burocráticos } \\
\text { Sí } \\
\text { No } \\
\text { No sabe }\end{array}$ & $\begin{array}{l}80.0 \\
10.0\end{array}$ & 100.0 & 100.0 & 100.0 & $\begin{array}{r}95.0 \\
2.5\end{array}$ \\
\hline $\begin{array}{l}\text { No sabe } \\
\text { No respondió } \\
\text { Ofrec. financ. para inversión }\end{array}$ & 10.0 & & & & 2.5 \\
\hline $\begin{array}{l}\text { Sí } \\
\text { No } \\
\text { No sabe } \\
\text { No respondió }\end{array}$ & $\begin{array}{l}90.0 \\
10.0\end{array}$ & $\begin{array}{l}30.0 \\
70.0\end{array}$ & $\begin{array}{l}30.0 \\
70.0\end{array}$ & $\begin{array}{l}30.0 \\
70.0\end{array}$ & $\begin{array}{r}22.5 \\
75.0 \\
2.5\end{array}$ \\
\hline $\begin{array}{l}\text { Total } \\
\text { Sí } \\
\text { No } \\
\text { No sabe } \\
\text { No respondió }\end{array}$ & $\begin{array}{r}41.3 \\
51.3 \\
6.3 \\
1.3\end{array}$ & $\begin{array}{r}75.0 \\
23.8 \\
1.3\end{array}$ & $\begin{array}{l}82.5 \\
17.5\end{array}$ & $\begin{array}{r}80.0 \\
11.3 \\
8.8\end{array}$ & $\begin{array}{r}69.7 \\
25.9 \\
4.1 \\
0.3\end{array}$ \\
\hline
\end{tabular}

FUENTE: Encuesta COSIMCED. 
maquiladoras a favor de México, las respuestas más frecuentes fueron el facilitarles los trámites burocráticos y el obligarlas a comprar insumos nacionales y a pagar mejores sueldos a sus trabajadores, así como a ofrecerles mejor infraestructura y exigirles mejores prestaciones para sus empleados (cuadros 29 y 30 ).

Finalmente, cuando se les inquirió acerca de su opinión en cuanto a lo que pasaría con las maquiladoras en un futuro previsible, todos ellos (100\%) opinaron que no disminuirían en número; el $30 \%$ consideró que aumentarán al mismo ritmo en que lo han hecho en el pasado y el $67.5 \%$ consideraron que aumentarán más rápidamente que en el pasado (cuadro 31 ).

CUADRO 31. Líderes de opinión. ¿Qué cree usted que pasará en el futuro previsible con las maquiladoras de México?.

\begin{tabular}{|c|c|c|c|c|c|c|c|c|}
\hline \multirow[t]{2}{*}{ Ciudad } & \multicolumn{2}{|c|}{$\begin{array}{l}\text { Aumentarán } \\
\text { más rápido }\end{array}$} & \multicolumn{2}{|c|}{$\begin{array}{l}\text { Aumentarán } \\
\text { igual }\end{array}$} & \multicolumn{2}{|c|}{$\begin{array}{l}\text { No aumentarán } \\
\text { ni disminuiran }\end{array}$} & \multicolumn{2}{|c|}{ Total } \\
\hline & Abs. & $\%$ & Abs. & $\%$ & Abs. & $\%$ & Abs. & $\%$ \\
\hline Ciudad Juárez & 3 & 11.1 & 7 & 58.3 & & & 10 & 25.0 \\
\hline Nuevo Laredo & 8 & 29.6 & 2 & 16.7 & & & 10 & 25.0 \\
\hline Tijuana & 9 & 33.3 & 1 & 8.3 & & & 10 & 25.0 \\
\hline Guadalajara & 7 & 25.9 & 2 & 16.7 & 1 & 100.0 & 10 & 25.0 \\
\hline Total & 27 & 100.0 & 12 & 100.0 & 1 & 100.0 & 40 & 100.0 \\
\hline
\end{tabular}

FUENTE: Encuesta COSIMCED.

\section{Reflexiones finales}

Con base en lo antes expuesto, puede decirse que, por lo menos desde el punto de vista de los trabajadores maquiladores y los líderes de opinión de las comunidades donde operan, las maquiladoras representan una importante y positiva fuente de empleo, ingresos y actividad económica regionales. Incluso, puede decirse también que, en su apreciación, los trabajadores y los líderes ubican a la maquila como un fenómeno que tiene más impactos positivos que negativos en las condiciones de vida de la comunidad.

Debe reconocerse que esos resultados no son suficientes como para resolver el debate en cuanto a las ventajas y/o desventajas que representan las maquiladoras para el futuro desarrollo de la sociedad mexicana. En todo caso, deberían complementarse con una evaluación a fondo de otros tipos de impacto, tanto a nivel nacional como regional, en los diferentes 
ámbitos de la vida de los mexicanos. Sin embargo, los resultados de la encuesta aqui expuestos son aprovechados sobre todo porque pueden servir de gufa en el diseño de futuros estudios que tengan como objetivo conocer una evaluación subjetiva de los directamente involucrados o relacionados con la industria maquiladora de exportación.

\section{BIBLIOGRAFÍA}

BANCO DE MÉXICO. 1986. Indicadores económicos. Diciembre.

BEARRASEN, Donald. 1973. The Border Industrializacion Program of Mexico. Lexington Books.

CARRILLO Huerta, Mario y Víctor L. Urquidi. 1989. "Trade Deriving from the International Division of Production: Maquila and Postmaquila in Mexico", Journal of the Flagstaff Institute. Vol. XIII, no. 1.

FERNÁNDEZ, José Luis y Bertha Elena de Buen. 1984. "Los límites del programa de industrialización fronteriza para el abatimiento de las tasas de desocupación y la calificación de la fuerza de trabajo". En: Eliseo Mendoza Berrueto (Coord.). Impactos regionales de las relaciones econbmicas México-Estados Unidos. El Colegio de México y Asociación de Estudios Regionales México-Estados Unidos. México.

GRUNWALD, Joseph y Kenneth Flamm. 1985. The global factory. Foreingn in international trade. Washington, the Brookings in Institution.

INEGI. 1986. Estadistica de la industria maquiladora de exportación 1975-1985. INEGI-SPP, México.

INEGI. 1989. Avance de información económica. Industria maquiladora de exportación. México, INEGI-SPP, mayo.

MARÍA Y CAMPOS, Mauricio de. 1986. La industria maquiladora de exportación en México. Antecedentes, evolución y perspectivas. Tex to de la presentación ante la Comisión de Comercio y Fomento Industrial de la LIII Legislatura de la H. Cámara de Diputados en la ciudad de México al 18 de agosto de 1986.

MARTÍNEZ DEL CAMPO, Manuel. 1986. "Transferencia de tecnología en la industria maquiladora de exportación. Informe de resultados", (inédito). El Colegio de México, México.

RIVAS F., Sergio. 1985. "La industria maquiladora en México". Comercio Exterior. Vol. 35, no. 11. 